Defraeye T., Blocken B., Carmeliet J. (2011), An adjusted temperature wall function for turbulent forced convective heat transfer for bluff bodies in the atmospheric boundary layer, Building and Environment 46 (11), 2130-2141. http://dx.doi.org/10.1016/..buildenv.2011.04.013

\title{
An adjusted temperature wall function for turbulent forced convective heat transfer for bluff bodies in the atmospheric boundary layer
}

\author{
Thijs Defraeye ${ }^{\mathrm{a}, \mathrm{b},{ }^{*}}$, Bert Blocken ${ }^{\mathrm{c}}$ and Jan Carmeliet ${ }^{\mathrm{d}, \mathrm{e}}$ \\ ${ }^{a}$ Division of Mechatronics, Biostatistics and Sensors, Department of Biosystems, Katholieke Universiteit \\ Leuven, Willem de Croylaan 42, 3001 Heverlee, Belgium \\ ${ }^{b}$ Laboratory of Building Physics, Department of Civil Engineering, Katholieke Universiteit Leuven,
} Kasteelpark Arenberg 40, 3001 Heverlee, Belgium

${ }^{c}$ Building Physics and Systems, Eindhoven University of Technology, P.O. Box 513, 5600 Eindhoven, The Netherlands

${ }^{d}$ Chair of Building Physics, Swiss Federal Institute of Technology Zurich (ETHZ), Wolfgang-Pauli-

Strasse 15, 8093 Zürich, Switzerland

${ }^{e}$ Laboratory for Building Science and Technology, Swiss Federal Laboratories for Materials Testing and Research (Empa), Überlandstrasse 129, 8600 Dübendorf, Switzerland

\begin{abstract}
Accurate convective heat transfer predictions are required in building engineering and environmental studies on urban heat islands, building energy performance, building-envelope durability or conservation and (natural) ventilation of buildings. When applying computational fluid dynamics (CFD) for these computationally-expensive studies at high-Reynolds numbers, wall functions are mostly used to model the boundary-layer region. In this study, an adjustment to the standard temperature wall function is proposed for forced convective heat transfer at surfaces of typical wall-mounted bluff bodies in turbulent boundary layers, such as the atmospheric boundary layer, at moderate to high Reynolds numbers. The methodology to determine this customised temperature wall function (CWF) from validated numerical data of CFD simulations using low-Reynolds number modelling (LRNM) is explained, where a logarithmic-law behaviour is found. The performance of this CWF is evaluated for several bluff-body configurations. Standard wall functions (SWFs) yield deviations of about $40 \%$ for the convective heat transfer coefficient, compared to LRNM. With the CWF however, these deviations are reduced to about $10 \%$ or lower. The CWF therefore combines increased (wall-function) accuracy for convective heat transfer predictions with the typical advantage of wall functions compared to LRNM, being a lower grid resolution in the near-wall region, which increases computational economy and facilitates grid generation. Furthermore, this CWF can be easily implemented in existing CFD codes, and is implemented in the commercial CFD code Fluent in this study.
\end{abstract}

\footnotetext{
* Corresponding author. Tel.: +32 (0)16321618; fax: +32 (0) 16322966.

E-mail address: thijs.defraeye@ biw.kuleuven.be
} 
Defraeye T., Blocken B., Carmeliet J. (2011), An adjusted temperature wall function for turbulent forced convective heat transfer for bluff bodies in the atmospheric boundary layer, Building and Environment 46 (11), 2130-2141. http://dx.doi.org/10.1016/..buildenv.2011.04.013

\section{Keywords}

wall function; computational fluid dynamics; RANS; convective heat transfer coefficient; cube; urban heat transfer

\section{Nomenclature}

A slope

$B \quad$ intercept

$c_{p} \quad$ specific heat capacity of air $(\mathrm{J} / \mathrm{kg} . \mathrm{K})$

$C_{\mu} \quad$ coefficient used in the k- $\varepsilon$ turbulence models (0.09)

E constant in wall-function expression (9.793)

$H \quad$ cube height (m)

$k \quad$ turbulent kinetic energy $\left(\mathrm{m}^{2} / \mathrm{s}^{2}\right)$

$k_{P} \quad$ turbulent kinetic energy in cell centre point $P$ of wall-adjacent cell $\left(\mathrm{m}^{2} / \mathrm{s}^{2}\right)$

$P \quad$ cell centre point of wall-adjacent cell

$P_{J} \quad$ empirically determined coefficient (function of $P r_{t}$ )

Pr molecular Prandtl number

$P_{t} \quad$ turbulent Prandtl number

$\operatorname{Pr}_{t, C W F}$ turbulent Prandtl number used by CWF

$q_{c, w} \quad$ convective heat flux at the surface $\left(\mathrm{W} / \mathrm{m}^{2}\right)$

Re Reynolds number

$T \quad$ air temperature $\left({ }^{\circ} \mathrm{C}\right)$

$T_{P} \quad$ temperature in cell centre point $P$ of wall-adjacent cell $\left({ }^{\circ} \mathrm{C}\right)$

$T_{P}{ }^{*} \quad$ dimensionless temperature in cell centre point $P$ of wall-adjacent cell

$T_{\text {ref }} \quad$ reference temperature $\left({ }^{\circ} \mathrm{C}\right)$

$T_{w} \quad$ wall temperature $\left({ }^{\circ} \mathrm{C}\right)$

$T^{+} \quad$ dimensionless temperature, $\rho c_{p} u_{\tau}\left(T_{w}-T\right) / q_{c, w}$

$T^{*} \quad$ dimensionless temperature

$u_{A B L}{ }^{*} \quad$ ABL friction velocity $(\mathrm{m} / \mathrm{s})$

$u_{\tau} \quad$ boundary-layer friction velocity, $\left(\tau_{w} / \rho\right)^{1 / 2}(\mathrm{~m} / \mathrm{s})$

$U \quad$ mean air speed $(\mathrm{m} / \mathrm{s})$

$U_{10} \quad$ mean air speed in the undisturbed flow at a height of $10 \mathrm{~m}$ above the ground $(\mathrm{m} / \mathrm{s})$

$U^{+} \quad$ dimensionless mean air speed, $U / u_{\tau}$

$U^{*} \quad$ dimensionless mean air speed

$y \quad$ distance (normal) from the wall (m)

$y_{P} \quad$ distance (normal) of cell centre point $P$ of wall-adjacent cell to the wall (m)

$y_{P}{ }^{+} \quad$ dimensionless wall (normal) distance of cell centre point $P$ of wall-adjacent cell, $u_{\tau} y_{P} / v$

$y_{P} * \quad$ dimensionless wall (normal) distance of cell centre point $P$ of wall-adjacent cell

$y_{T}{ }^{*} \quad$ lower limit for temperature wall function 
Defraeye T., Blocken B., Carmeliet J. (2011), An adjusted temperature wall function for turbulent forced convective heat transfer for bluff bodies in the atmospheric boundary layer, Building and Environment 46 (11), 2130-2141. http://dx.doi.org/10.1016/..buildenv.2011.04.013

$y^{+} \quad$ dimensionless wall (normal) distance, $u_{z} y / v$

$y^{*} \quad$ dimensionless wall (normal) distance

$z \quad$ height above the ground $(\mathrm{m})$

$z_{0} \quad$ aerodynamic roughness length $(\mathrm{m})$

Greek symbols

$\varepsilon \quad$ turbulence dissipation rate $\left(\mathrm{m}^{2} / \mathrm{s}^{3}\right)$

$\kappa \quad$ von Karman constant $(0.4187)$

$\mu \quad$ dynamic viscosity of air $(\mathrm{kg} / \mathrm{ms})$

$v \quad$ kinematic viscosity of air $\left(\mathrm{m}^{2} / \mathrm{s}\right)$

$\rho \quad$ density of air $\left(\mathrm{kg} / \mathrm{m}^{3}\right)$

$\tau_{w} \quad$ wall shear stress $\left(\mathrm{kg} / \mathrm{ms}^{2}\right)$

$\varphi \quad$ incidence angle $\left({ }^{\circ}\right)$

\section{Abbreviations}

ABL atmospheric boundary layer

CFD computational fluid dynamics

CHTC convective heat transfer coefficient

CWF customised wall function

DNS direct numerical simulation

LES large-eddy simulation

LRNM low-Reynolds number modelling

RANS Reynolds-averaged Navier-Stokes

SWF standard wall function

WF wall function

Subscripts

$\begin{array}{ll}\text { LRNM } & \text { low-Reynolds number modelling } \\ \text { P } & \text { cell centre point } P \text { of wall-adjacent cell } \\ \text { WF } & \text { wall function }\end{array}$

\section{Introduction}

Forced convective heat transfer at surfaces of wall-mounted bluff bodies in turbulent boundary layers at moderate to high Reynolds numbers $\left(R e=10^{4}-10^{7}\right)$ is of interest in many engineering applications, such as the evaluation of wind-induced convective heat losses from building surfaces or building components (e.g. solar collectors) in the atmospheric boundary layer (ABL). In building and urban engineering, convective heat transfer predictions are especially relevant for ABL flow applications on urban heat islands [1,2], building (component) energy performance [3,4], building-envelope durability or 
Defraeye T., Blocken B., Carmeliet J. (2011), An adjusted temperature wall function for turbulent forced convective heat transfer for bluff bodies in the atmospheric boundary layer, Building and Environment 46 (11), 2130-2141. http://dx.doi.org/10.1016/..buildenv.2011.04.013

conservation [5,6] and (natural) ventilation of buildings [7]. Furthermore, they can be used to estimate the convective moisture transfer from building surfaces, by using the heat and mass transfer analogy [8].

Convective moisture transfer is especially of interest for hygrothermal analysis of building envelopes and for urban applications involving evaporation of water from ponds, roof ponds, green roofs, green walls or surfaces which are wetted by (wind-driven) rain [9].

Convective heat transfer research for this type of flow problem is mainly performed by wind-tunnel experiments [10-14] and by computational fluid dynamics (CFD) studies [15-17] for both isolated bodies as well as arrays of bluff bodies. Compared to wind-tunnel experiments, CFD simulations have the advantage that usually a higher spatial resolution is obtained. With CFD also no restrictions are imposed regarding scaling and accessibility of certain surfaces, in contrast to wind-tunnel infrared thermography measurements [11] for example, which is especially important for more complex configurations. On the other hand, the applied numerical modelling approaches determine to a large extent the accuracy of CFD simulations.

At high Reynolds numbers $\left(R e \approx 10^{6}-10^{7}\right)$, CFD computations for this type of flow are often performed with (steady) Reynolds-averaged Navier-Stokes (RANS) combined with wall functions (WFs) [18], especially for complex configurations, for example in large-scale environmental studies [6,7,19-22]. WFs are used here to take care of the boundary-layer region, instead of low-Reynolds number modelling (LRNM), mainly for reasons of computational economy: at high Reynolds numbers, the use of WFs, which model the flow quantities in the boundary-layer region by calculating them by means of semiempirical functions, avoids an extremely high grid resolution here, which would be required for LRNM, where the boundary layer is resolved explicitly. Both boundary-layer modelling approaches are described more in detail below (section 3).

The standard formulation for WFs [23], referred to as standard wall functions (SWFs), however has two main limitations:

1. SWFs impose strict requirements to the computational grid: the cell centre point $P$ of the walladjacent cell has to be located outside of the viscosity-affected region (viscous sublayer and buffer layer), i.e. $y_{P}{ }^{+}>30$. On the other hand, the point $P$ has to be located close enough to the wall for it to be in the logarithmic layer, i.e. $y_{P}{ }^{+}<500$ [24], and to ensure a sufficiently high grid resolution in the boundary layer. The dimensionless wall distance of point $P\left(y_{P}{ }^{+}\right)$is defined as:

$$
\mathrm{y}_{\mathrm{P}}{ }^{+}=\frac{\sqrt{\frac{\tau_{\mathrm{w}}}{\rho}} \mathrm{y}_{\mathrm{P}}}{v}
$$

where $y_{P}$ is the distance (normal) from the cell centre point $P$ of the wall-adjacent cell to the wall, $\tau_{w}$ is the shear stress at the wall, $\rho$ is the air density and $v$ is the kinematic viscosity of air. For complex flows, these $y_{P}{ }^{+}$criteria are difficult to achieve throughout the entire computational domain, especially if automated grid generation is used, by which WFs are sometimes used outside of their specified validity range.

2. The wall-function concept of SWFs is based on a universal behaviour of the boundary layer, in terms of velocity, turbulence and temperature profiles. These SWFs are derived for wall-attached boundary 
Defraeye T., Blocken B., Carmeliet J. (2011), An adjusted temperature wall function for turbulent forced convective heat transfer for bluff bodies in the atmospheric boundary layer, Building and Environment 46 (11), 2130-2141. http://dx.doi.org/10.1016/..buildenv.2011.04.013

layers under so-called equilibrium conditions, i.e. small pressure gradients, local equilibrium between generation and dissipation of turbulent energy and a constant (uniform) shear stress and heat flux in the near-wall region [25]. This wall-function concept breaks down for more complex flows, such as flow around bluff bodies where the boundary layer does not remain attached to the surface. SWFs can therefore lead to inaccurate predictions, especially for wall friction and convective heat transfer $[25,26]$.

In order to obviate these two limitations of SWFs to some extent, more advanced approaches have been developed in the past, which were mainly focused on WFs for velocity rather than for temperature.

A first group of researchers aimed at developing a more generalised treatment for WFs. This generalisation involved extending the applicability of wall functions throughout the entire lower part of the boundary layer, i.e. by allowing the cell centre point $P$ to be located in the viscosity-affected region, i.e. $y_{P}{ }^{+}<30$. Some authors therefore proposed a single wall-function expression which is valid throughout the lower part of the boundary layer $\left(y_{P}{ }^{+}<500\right)$ [27-30]. Most of these expressions were however derived for equilibrium boundary layers and usually only for velocity and temperature, thus not considering the variation of turbulence parameters. Others [31] adopted an approach which uses a LRNM or wall-function formulation, depending on the $y_{P}{ }^{+}$value, to determine the flow quantities in the walladjacent cell. A smooth transfer between both formulations was achieved by blending. Although these generalised approaches allow for very low $y_{P}{ }^{+}$values (i.e. of the wall-adjacent cell), the remainder of the viscous sublayer and the buffer layer, located in the second and successive wall-normal cells, is then often resolved by the high-Reynolds number turbulence model. Since these models are actually not designed for this purpose, the accuracy of the boundary-layer predictions can be compromised [32].

A second group aimed at improving the accuracy of WFs for complex, non-equilibrium flows, within the typical application range of WFs $\left(y_{P}{ }^{+}>30\right)$. Some of these adjusted WFs are still essentially based on the logarithmic law [29,33-38]. Others proposed more advanced strategies [31,39-42]. Some of these adjusted WFs were used in combination with a generalised wall treatment, as discussed in the previous paragraph. Note that consistency between these adjusted WFs and the applied turbulence model should be ensured $[41,43]$. These adjusted WFs are considered very valuable achievements and can significantly improve accuracy regarding air flow and heat transfer.

The accuracy of these adjusted WFs however does not always improve significantly compared to SWFs. One of the reasons is that SWFs do not necessarily result in worse overall flow predictions compared to LRNM or adjusted wall-function approaches, for example for bluff bodies with sharp edges or a backward-facing step at high Reynolds numbers $[31,44,45]$. In this case, the boundary-layer separation points are prescribed by the geometry and relatively thin boundary layers are found. Thus the near-wall interventions do not have a significant influence on the overall flow field in such cases. For convective heat transfer however, which is strongly determined by the heat transport in the boundary layer, a standard (temperature) WF is found to be inappropriate $[15,26,45,46]$ and more accurate alternatives are required. Also for applications in which wall friction is of interest, e.g. for drag predictions, increased accuracy is required [47]. Furthermore, the implementation of these adjusted WFs in commercial CFD codes is not always that straightforward due to the limited access to the code itself. 
Defraeye T., Blocken B., Carmeliet J. (2011), An adjusted temperature wall function for turbulent forced convective heat transfer for bluff bodies in the atmospheric boundary layer, Building and Environment 46 (11), 2130-2141. http://dx.doi.org/10.1016/..buildenv.2011.04.013

From the viewpoint of improved wall-function accuracy for convective heat transfer for complex, non-equilibrium flows and ease of implementation in existing CFD codes, an adjustment to the standard temperature WF is proposed in this paper, which classifies within the second group of advanced WF approaches mentioned above. This customised temperature WF (CWF) focuses on applications for forced convective heat transfer at the surfaces of wall-mounted (sharp-edged) bluff bodies in turbulent boundary layers at moderate to high Reynolds numbers. A typical example is a building in the atmospheric boundary layer. The methodology to determine this CWF from validated numerical CFD (LRNM) simulation data is explained. This CWF is essentially based on a logarithmic law and is determined for flow over a cubic building model. Afterwards, this CWF is implemented in a commercial CFD code in a straightforward way. The performance of this CWF, compared to LRNM and the SWF, is evaluated for several bluff-body configurations and its limitations are discussed. In the next section, the numerical model of the cubic building is described.

\section{Numerical model}

A cube with a height $(H)$ of $10 \mathrm{~m}$ is considered, representing a building in the ABL. The size of the computational domain (Figure 1) is determined according to the guidelines of Franke et al. [24] and Tominaga et al. [48]. The blockage ratio, which is the ratio of the frontal area of the cube $\left(H^{2}\right)$ to the surface area of the inlet of the computational domain $\left(21 \times 6 H^{2}\right)$, is $0.8 \%$. The computational domain allows an evaluation of different incidence angles $(\varphi)$, namely for $\varphi=0^{\circ}-90^{\circ}$. The incidence angle is the angle between the approach-flow wind direction and the normal to the surface of interest (see Figure 1). It is equal to $0^{\circ}$ for flow perpendicular to the surface and increases in a clockwise manner. At the inlet of the domain, the vertical profiles of the mean (horizontal) wind speed $U$ (logarithmic law), turbulent kinetic energy $k$ and turbulence dissipation rate $\varepsilon$ are imposed, according to Richards and Hoxey [49]. These profiles represent a neutral ABL, i.e. where turbulence originates only from friction and shear and not from thermal stratification:

$$
\begin{aligned}
& \mathrm{U}(\mathrm{z})=\frac{\mathrm{u}_{\mathrm{ABL}}^{*}}{\kappa} \ln \left(\frac{\mathrm{z}+\mathrm{z}_{0}}{\mathrm{z}_{0}}\right) \\
& \mathrm{k}=\frac{\mathrm{u}_{\mathrm{ABL}}^{*}}{\sqrt{\mathrm{C}_{\mu}}} \\
& \varepsilon=\frac{\mathrm{u}_{\mathrm{ABL}}^{*}{ }^{3}}{\kappa\left(\mathrm{z}+\mathrm{z}_{0}\right)}
\end{aligned}
$$

where $u_{A B L}{ }^{*}$ is the ABL friction velocity, $\kappa$ is the von Karman constant (0.4187), $z$ is the height above the ground, $z_{0}$ is the aerodynamic roughness length and $C_{\mu}$ is a coefficient (0.09). The ABL friction velocity is linked to a reference wind speed, namely $U_{10}$ in this study, which is the mean wind speed at a height of $10 \mathrm{~m}$ above the ground, and is taken equal to $0.5 \mathrm{~m} / \mathrm{s}$. The reason for this rather low value is explained later. Other wind speeds $\left(U_{10}=0.05-2.5 \mathrm{~m} / \mathrm{s}\right)$ are also evaluated in section 4.2 . The parameter $z_{0}$ is 0.03 $\mathrm{m}$, which corresponds to a land surface with low vegetation (e.g. grass) and isolated obstacles [50]. The temperature of the approach flow is $10^{\circ} \mathrm{C}$. Wind at different incidence angles is evaluated, namely at incidence angles of $0^{\circ}, 15^{\circ}, 30^{\circ}$ and $45^{\circ}$. Due to the symmetry of the cube, evaluation of larger incidence 
Defraeye T., Blocken B., Carmeliet J. (2011), An adjusted temperature wall function for turbulent forced convective heat transfer for bluff bodies in the atmospheric boundary layer, Building and Environment 46 (11), 2130-2141. http://dx.doi.org/10.1016/i.buildenv.2011.04.013

angles $\left(60^{\circ}, 75^{\circ}, 90^{\circ}, \ldots\right)$ is not necessary since these cases can be related to one of the previously mentioned simulations $\left(\varphi=0^{\circ}-45^{\circ}\right)$ by considering a different surface.

The ground boundary is modelled as a no-slip boundary with zero roughness since surface roughness values cannot be specified if LRNM is used [51]. This restriction will inevitably introduce streamwise gradients in the vertical profiles of mean horizontal wind speed and turbulence [52,53] but this effect is rather limited since a short upstream fetch is considered, as recommended by Blocken et al. [52].

Although WFs, in contrast to LRNM, can account for surface roughness of the ground surface in order to avoid these streamwise gradients, no roughness is specified for the wall-function simulations either since a comparison between both simulations methods will be made. The ground boundary is taken adiabatic.

The exterior surfaces of the cube are modelled as no-slip boundaries with zero roughness and have an imposed constant temperature of $20^{\circ} \mathrm{C}$. Note that, since the focus is on forced convection, the flow field is independent of the thermal boundary conditions (see section 3). For the top boundary of the computational domain, a symmetry boundary condition (slip wall) is used, which assumes that the normal velocity component and the normal gradients at the boundary are zero. Zero static pressure is imposed at the outlet. Note that symmetry boundary conditions are used for the lateral boundaries for an incidence angle of $0^{\circ}$ and inlet or outlet boundary conditions are used for other incidence angles (Figure 1).

Two types of grid are used in this study: a LRNM grid and a wall-function grid. Both grids are built based on a grid sensitivity analysis. Both grids are hybrid grids (hexahedral and prismatic cells). The LRNM grid consists of about $2.7 \times 10^{6}$ cells for LRNM (Figure 1). In order to resolve the boundary layer appropriately, LRNM grids require a high cell density in the wall-normal direction and a small $y^{+}$value of the wall-adjacent cell $\left(y_{P}{ }^{+} \approx 1\right)$, compared to WFs $\left(30<y_{P}{ }^{+}<500\right)$. For the LRNM grid, the highest $y_{P}{ }^{+}$ values are attained at the edges of the windward surface (for $\varphi=0^{\circ}$ ) but are smaller than 3 for all wind speeds evaluated in this study. The lower number of computational cells for WFs, compared to LRNM, significantly reduces the required computational time. Note that, while the total number of LRNM cells for an isolated building is still relatively small, computationally-expensive large-scale building engineering or environmental studies using LRNM might become quasi impossible because LRNM yields too many cells. In this case, the use of WFs is the only option. WFs are therefore not only beneficial, but will often also be decisive.

Since $\tau_{w}$ increases with increasing wind speed $\left(U_{10}\right)$, the evaluation of higher wind speeds with LRNM requires locally a higher grid resolution in the boundary-layer region, hence a lower $y_{P}$, in order to obtain a $y_{P}{ }^{+}$of about 1 (see Eq.(1)). The required $y_{P}$ can therefore become very small for LRNM at high Reynolds numbers ( $\pm 0.05 \mathrm{~mm}$ for $U_{10}=7.5 \mathrm{~m} / \mathrm{s}$, see Defraeye et al. [16]) which significantly increases the computational expense, but which can also entail considerable problems for grid generation and convergence rates. These are actually the main reasons to employ WFs at high Reynolds numbers. Relatively low wind speeds $\left(U_{10}\right)$ are therefore used in this study to limit $y_{P}$ for LRNM grids to some extent (see Defraeye et al. [16]).

The wall-function grid has the same cell density as the LRNM grid outside the near-wall region, but in the near-wall region the grid is adapted in order to provide a higher $y_{P}{ }^{+}$value for the wall-adjacent cell as well as a smooth transition with the second and successive wall-normal cells, with respect to grid 
Defraeye T., Blocken B., Carmeliet J. (2011), An adjusted temperature wall function for turbulent forced convective heat transfer for bluff bodies in the atmospheric boundary layer, Building and Environment 46 (11), 2130-2141. http://dx.doi.org/10.1016/..buildenv.2011.04.013

stretching. This resulted in a grid of about $1.6 \times 10^{6}$ cells with $y_{P}{ }^{+}$values between about 20 and 400 on the cube surface (at $0.5 \mathrm{~m} / \mathrm{s}$ ).

\section{Numerical simulation}

The simulations are performed with the CFD code Fluent 6.3, which uses the control volume method. Steady RANS is used in combination with a turbulence model. The realizable k- $\varepsilon$ model [54] is used together with LRNM and WFs, which take care of the viscosity-affected region. Experimental validation is presented below in section 4 .

For the k- $\varepsilon$ model, together with LRNM, a two-layer approach is adopted. The turbulent core region of the flow is resolved by the $\mathrm{k}-\varepsilon$ model, for which these models were primarily developed. LRNM is used to resolve the viscosity-affected region, for which the one-equation LRNM Wolfshtein model [55] is used.

If WFs are used for boundary-layer modelling, the flow quantities in the cell centre point $P$ of the wall-adjacent cell are calculated by means of semi-empirical functions, instead of resolving the boundary layer explicitly. WFs are usually expressed in terms of dimensionless parameters, namely $y^{+}, U^{+}$and $T^{+}$, which are functions of the shear stress at the wall $\left(\tau_{w}\right)$. In complex flows however, $\tau_{w}$ can become zero, for example in stagnation and reattachment points. Therefore, other dimensionless parameters are used to express WFs in most existing CFD codes, namely $y^{*}, U^{*}$ and $T^{*}$, which are related to the turbulent kinetic energy $k$ :

$$
\begin{aligned}
\mathrm{y}^{*} & =\frac{\rho \mathrm{C}_{\mu}^{1 / 4} \mathrm{k}^{1 / 2} \mathrm{y}}{\mu} \\
\mathrm{U}^{*} & =\frac{\rho \mathrm{C}_{\mu}^{1 / 4} \mathrm{k}^{1 / 2} \mathrm{U}}{\tau_{\mathrm{w}}} \\
\mathrm{T}^{*} & =\frac{\rho \mathrm{C}_{\mu}^{1 / 4} \mathrm{k}^{1 / 2}\left(\mathrm{~T}_{\mathrm{w}}-\mathrm{T}\right) \mathrm{c}_{\mathrm{p}}}{\mathrm{q}_{\mathrm{c}, \mathrm{w}}}
\end{aligned}
$$

where $y$ is the distance (normal) from the wall, $\mu$ is the dynamic viscosity of air, $U$ is the air speed, $T$ is the air temperature and $c_{p}$ is the specific heat capacity of air. Furthermore, $y^{*}, U^{*}$ and $T^{*}$ are the dimensionless wall distance, air speed and temperature, respectively. Note that these parameters are equal to $y^{+}, U^{+}$and $T^{+}$, respectively, for boundary layers under equilibrium conditions, but they can differ significantly for more complex flows. Therefore, the parameters $y^{*}, U^{*}$ and $T^{*}$ will be used throughout this paper. The SWF for temperature (in Fluent 6.3) is given as a logarithmic law:

$$
\mathrm{T}_{\mathrm{P}}{ }^{*}=\mathrm{Pr}_{\mathrm{t}}\left(\frac{1}{\mathrm{\kappa}} \ln \left(\mathrm{Ey}_{\mathrm{P}}{ }^{*}\right)+\mathrm{P}_{\mathrm{J}}\right) \quad \mathrm{y}_{\mathrm{P}}{ }^{*}>\mathrm{y}_{\mathrm{T}}{ }^{*}=11.639
$$

where $P r_{t}$ is the turbulent Prandtl number for air (0.85), $E$ is a constant (9.793) and $P_{J}$ is an empiricallydetermined coefficient, which is a function of $P r_{t}$ and is equal to -1.12 (default value) in this case. All the previously mentioned numerical values in Eq.(6) are the default values in Fluent 6.3. The lower limit for this SWF (in Fluent 6.3) is also given, namely $y_{T}^{*}$. For cells which have a $y_{P} *$ below this value, $T_{P} *$ is determined by means of a linear law, which intersects with the logarithmic law at $y_{T}{ }^{*}$ : 
Defraeye T., Blocken B., Carmeliet J. (2011), An adjusted temperature wall function for turbulent forced convective heat transfer for bluff bodies in the atmospheric boundary layer, Building and Environment 46 (11), 2130-2141. http://dx.doi.org/10.1016/..buildenv.2011.04.013

$$
\mathrm{T}_{\mathrm{P}}{ }^{*}=\operatorname{Pr} \mathrm{y}_{\mathrm{P}}{ }^{*} \quad \mathrm{y}_{\mathrm{P}}{ }^{*}<\mathrm{y}_{\mathrm{T}}{ }^{*}=11.639
$$

where $P r$ is the molecular Prandtl number. When using wall functions, the first cell should however be located in the logarithmic region $\left(y_{P} *>30\right)$. The combination of the linear and logarithmic law (Eqs.(7)(8)) is called the law-of-the-wall for temperature. Note that, since the $y_{P} *$ value is used by WFs, wallfunction grids, to be used for non-equilibrium flows, have to be built to have a $y_{P} *$ value of about 30-500, instead of a $y_{P}{ }^{+}$value within this range. These $y_{P} *$ values for the wall-function grid of the cube are presented in detail in section 5.1.

Furthermore, second-order discretisation schemes are used throughout. The SIMPLE algorithm is used for pressure-velocity coupling. Pressure interpolation is second order. Since the focus of this paper is on forced convection, buoyancy effects are not taken into account in the simulations, by which the flow field is independent of the imposed thermal boundary conditions. Thereby, rather low wind speeds could be used in the simulations in order to limit the required $y_{P}$ for LRNM (see Defraeye et al. [16]). Radiation is also not considered in the simulations since fixed temperature boundary conditions are used for the surfaces of the cube. Convergence was assessed by monitoring the velocity, turbulent kinetic energy and temperature on specific locations in the flow field and heat fluxes on the surfaces of the cube.

\section{Experimental validation}

The accuracy of CFD simulations depends to a large extent on the turbulence-modelling and boundarylayer modelling approaches that are used and therefore this has to be quantified by means of validation experiments/simulations. The accuracy of the realizable k- $\varepsilon$ turbulence model with LRNM was recently evaluated in a CFD validation study [46] using wind-tunnel measurements [11] of convective heat transfer on the surfaces of a cube placed in turbulent channel flow at a Reynolds number of $4.6 \times 10^{3}$, based on the cube height and the bulk wind speed. Convective heat transfer is frequently evaluated by the convective heat transfer coefficient (CHTC):

$$
\mathrm{CHTC}=\frac{\mathrm{q}_{\mathrm{c}, \mathrm{w}}}{\left(\mathrm{T}_{\mathrm{w}}-\mathrm{T}_{\mathrm{ref}}\right)}
$$

where $q_{c, w}$ is the convective heat flux at the wall, which is assumed positive away from the wall, $T_{w}$ is the surface temperature at the wall $\left(20^{\circ} \mathrm{C}\right.$ in this study) and $T_{r e f}$ is the approach-flow (reference) temperature $\left(10^{\circ} \mathrm{C}\right.$ in this study). A part of the results of this validation study is shown in Figure 2 . The CHTCs on the windward and leeward surfaces of the cube in a vertical and horizontal centreplane from experiments and CFD simulations are given. Only the results in the central region of the surfaces are shown since discrepancies near the edge zones were attributed to the limited resolution of the experiments in these zones. The CFD validation study [46] produced accurate CHTC predictions, both in magnitude and distribution over the surface, for the windward surface (within the experimental uncertainty of 5\% in the overall part of the central region of the surface), and to a lesser extent for the leeward surface (differences with experimental data $<10 \%$ in the overall part of the central region of the surface). For the side and top surfaces, the distribution of the CHTC over these surfaces was less accurate. However, it is important to note that these discrepancies are rather attributed to inaccurate flow predictions in zones of separation and 
Defraeye T., Blocken B., Carmeliet J. (2011), An adjusted temperature wall function for turbulent forced convective heat transfer for bluff bodies in the atmospheric boundary layer, Building and Environment 46 (11), 2130-2141. http://dx.doi.org/10.1016/..buildenv.2011.04.013

recirculation around bluff bodies [56,57], due to steady-flow and turbulence modelling, than to inaccurate heat transfer modelling in the boundary layer. Such discrepancies are a generally known deficiency of the steady RANS approach combined with two-equation turbulence models. The surface-averaged CHTC values for all vertical surfaces however showed an acceptable agreement with the experimental data (see Table 1), especially given the fact that the experimental averaging of the CHTC was quite coarse, particularly at the edge zones. More advanced turbulence modelling approaches, for example large-eddy simulation (LES) or direct numerical simulation (DNS), could result in more accurate CHTC results on these surfaces. Nevertheless, steady RANS is still often preferred for complex configurations at high Reynolds numbers, such as large-scale urban and building aerodynamics studies [6,7,19-22,58,59], for reasons of computational economy, and will also be used in this study.

Note that, within the context of such steady RANS simulations, the flow field predicted by LRNM and by WFs will be quasi similar outside of the boundary layer since only an adjustment to the temperature wall function is made and buoyancy is not accounted for in the simulations. The discrepancies between WFs and LRNM will thus be mainly related to heat transport in the boundary-layer region, for which LRNM was shown to provide accurate results [46]. Therefore, it is considered justified to use these validated LRNM data to determine the proposed adjusted temperature WF, as explained below.

\section{Customised temperature wall function}

\subsection{Background}

In this section, the background regarding the proposed adjustment to the standard temperature WF is given. From the previously mentioned CFD study [46], which considered the same configuration, i.e. a cube immersed in a turbulent boundary layer, it was shown that SWFs significantly overestimated the CHTC ( $\pm 50 \%$ for $\varphi=0^{\circ}$ ), compared to LRNM. LRNM was found to provide accurate CHTC predictions by means of this CFD validation study. Note that a comparison of SWF and LRNM is discussed further in section 5.1 (Figure 6). Although LRNM and SWF near-wall modelling approaches showed significant differences in magnitude, the distribution of the CHTC over the surfaces was very similar. This similarity in distribution resulted from the fact that the flow fields were quite similar, since WFs did not have a significant effect on the flow field, due to the sharp-edged bluff-body geometry and the high Reynolds numbers that were considered (see section 1). The overestimation by SWFs could be explained (see Defraeye et al. [46]) by comparing the dimensionless temperature ( $\left.T^{*}\right)$ profiles for LRNM and SWFs for different positions at the windward surface along lines normal to the surface, as a function of the $y^{*}$ value. Such $T^{*}-y^{*}$ profiles are shown in Figure 3 for the simulations presented in this paper. For SWFs, $T^{*}$ of the wall-adjacent cells $\left(T_{P}{ }^{*}\right)$ is clearly forced, by means of Eq.(6), to a value that is systematically lower (point 1 in Figure 3) than the one found for LRNM at the same $y^{*}$ (point 2 in Figure 3). Since $T_{w}$ is imposed at the cube surface in this study $\left(T_{w}=20^{\circ} \mathrm{C}\right)$, this $T_{P}{ }^{*}$ value, calculated by SWFs (Eq.(6)), is used to calculate $q_{c, w}$ by means of Eq.(5). Since $k$ and $T$ in the wall-adjacent cell $\left(k_{P}\right.$ and $\left.T_{P}\right)$ for SWFs are found to agree quite well with those predicted by LRNM at the same $y^{*}$ value, the underprediction of $T_{P} *$ by SWFs (by $\pm 50 \%$ of $T_{P}{ }^{*}$ of LRNM, see Figure 3) will therefore mainly result, according to Eq.(5), in an overprediction of $q_{c, w}$. Based on Eq.(8), this overprediction leads to much higher CHTCs for SWFs ( \pm 
Defraeye T., Blocken B., Carmeliet J. (2011), An adjusted temperature wall function for turbulent forced convective heat transfer for bluff bodies in the atmospheric boundary layer, Building and Environment 46 (11), 2130-2141. http://dx.doi.org/10.1016/..buildenv.2011.04.013

$50 \%$ of $\mathrm{CHTC}_{\mathrm{LRNM}}$ for $\varphi=0^{\circ}$ ). Note that the good agreement between $k_{P}$ and $T_{P}$ of SWFs and LRNM (see Defraeye et al. [46]) mainly results from the similarity of both flow fields. Note that the SWF results do not agree with the law-of-the-wall throughout the boundary layer since equilibrium conditions, for which the law-of-the-wall was originally derived, do not apply.

However, a remarkable feature in Figure 3 is that the LRNM $T^{*}-y^{*}$ profiles correspond quite well for all positions on the windward surface. These profiles indicate a logarithmic-law behaviour, analogous to Eq.(6), at $y *$ values from about 100-4000 (line A) but also at $y^{*}$ values between about 20-100 (line B), however with a steeper slope. The $T^{*}-y^{*}$ profiles on other surfaces of the cube show a similar distribution with approximately the same profile (see section 4.2). This good agreement for all lines on different surfaces of the cube results from the fact that the parameters $y^{*}$ and $T^{*}$ are related to the turbulent kinetic energy, which in turn is strongly related to the turbulent heat transfer in the boundary layer (see Defraeye et al. [46]). Note that such an agreement is not found for the $T^{+}-y^{+}$profiles since these parameters are related to the shear stress. Since many different types of flow regimes are found on the cube surfaces (flow impingement, separation, reattachment), this seems to suggest that the universality in $T^{*}-y^{*}$ profiles is quasi independent of the flow regime.

The idea of an adjustment to the standard temperature wall function for such complex flow problems is based on the quasi-universality of these $T^{*}-y^{*}$ profiles for LRNM. Since for this specific flow problem, WFs have a rather limited impact on the overall flow field (see section 1), the SWF approach will still be applied to determine the other (non-thermal) flow quantities in the wall-adjacent cells. This customised temperature wall function (CWF) is based on fitting a logarithmic law, similar to Eq.(6), with validated numerical (LRNM) data for convective heat transfer in the turbulent region of the boundary layer (see Figure 3), i.e. for $y_{P} *>30$. Such logarithmic approximations are shown by line A (for $100<y_{P} *<4000$ ) and line B (for $20<y_{P} *<100$ ) in Figure 3, which have an adjusted slope and intercept, compared to Eq.(6), to provide a good fit to the LRNM data. Instead of the temperature SWF, which calculates $T_{P}{ }^{*}$ at point 1 in Figure 3, the CWF would calculate the $T_{P}{ }^{*}$ value at point 2 (according to line A), which is much closer to the LRNM data. Thereby, the CWF should result in more accurate $q_{c, w}$ and CHTC predictions. The only condition is that $k_{P}$ and $T_{P}$, i.e. in the wall-adjacent cell, for the CWF simulation are approximately equal to those of LRNM since these values are used by the CWF to calculate $q_{c, w}$ from $T_{P}{ }^{*}$ by means of Eq.(5). This is the case since: (1) the $k_{P}$ values of LRNM and SWFs were found to agree quite well (at $y^{*}$ values of the wall-adjacent cells for SWF, i.e. in the logarithmic region), due to the similarity of both flow fields. Furthermore, the velocity and turbulence fields of CWFs and SWFs are the same since only a temperature CWF is imposed and no buoyancy effects are taken into account, resulting in the same $k_{P}$ values in the wall-adjacent cells for CWFs and SWFs; and (2) the largest part of the temperature drop occurs in the lower part $\left(y^{*}<30\right)$ of the boundary layer (see Defraeye et al. [46]). Thereby, in this case $T_{P}$ will be almost equal to the approach-flow temperature $\left(10^{\circ} \mathrm{C}\right)$, for LRNM, SWFs and CWFs.

A more complex function could approximate the LRNM data throughout the entire $y^{*}$ range, i.e. a customised law-of-the-wall. Nevertheless, the focus will only be on the turbulent part of the boundary layer in this study (i.e. $y_{P}^{*}>30$ ) for reasons explained in section 4.4 , for which a logarithmic-law 
Defraeye T., Blocken B., Carmeliet J. (2011), An adjusted temperature wall function for turbulent forced convective heat transfer for bluff bodies in the atmospheric boundary layer, Building and Environment 46 (11), 2130-2141. http://dx.doi.org/10.1016/..buildenv.2011.04.013

approximation will be used. Thereby, the proposed CWF will thus only be applicable for typical wallfunction grids, i.e. grids with relatively high $y_{P} *$ values. For these grids, the difference between the standard law-of-the-wall and LRNM is however the largest (Figure 3), resulting in a higher effectiveness of the CWF, and the computational benefits are the highest.

\subsection{Applicability}

Before determining such a CWF from LRNM data, it is important to verify if the $T^{*}-y^{*}$ profiles, from which the CWF will be determined, are to some extent universally valid. This is required since the CWF needs to be more generally applicable than only for the case of the windward surface of a cube at incidence angles of $0^{\circ}$ at a specific wind speed. Therefore the influence of wind speed and incidence angle (wind direction) on the $T^{*}-y^{*}$ profiles will be investigated for the different surfaces of the cube. In section 5.2, the CWF will also be evaluated for other bluff-body geometries.

In Figure 4, the $T^{*}-y^{*}$ profiles are given for LRNM for three wind speeds, namely $U_{10}=0.05,0.5$ and $2.5 \mathrm{~m} / \mathrm{s}$. Note that the $y_{P}^{*}$ values are below 3 for all wind speeds. For low wind speeds, the influence of the overall flow field on the $T^{*}-y^{*}$ profiles is already manifested at low $y^{*}$ values, by which the logarithmic-like behaviour is not clearly found. At such low wind speeds, buoyancy effects will become dominant in reality, but they were not accounted for in the simulations in this study, since the focus was on forced convective flow. For high wind speeds, Figure 4 shows that the logarithmic behaviour simply extends to higher $y^{*}$ values, while following the same profile. Thereby, the applicability of the CWF for higher wind speeds is also ensured.

In Figure 5, the $T^{*}-y^{*}$ profiles are given along a line normal to the surface, where this line is positioned at the centre of a vertical surface, for incidence angles of $0^{\circ}$ to $180^{\circ}$ in steps of $15^{\circ}$. The profile along this centreline is representative for the profiles along the other lines on that surface for a specific wind direction, as in Figure 3, for all surfaces. Also note that, due to symmetry, only simulations for incidence angles of $0^{\circ}-45^{\circ}$ had to be performed. There is some variation of the profiles with the incidence angle, where the angles $45^{\circ}, 60^{\circ}$ and $135^{\circ}$ differ from the rest. Nevertheless, significantly higher $T^{*}$ values are found for LRNM for all incidence angles, compared to those of SWFs. Although not reported here, the $T^{*}-y^{*}$ profiles for the centreline on the top surface for all incidence angles all lie within the range of those of the vertical surfaces depicted in Figure 5.

Based on the results presented in this section, it can be concluded that there is a sufficient degree of universality in the $T^{*}-y^{*}$ profiles, with respect to the wind speed and wind direction, by which determining a CWF seems to make sense. The dependency of the $T^{*}-y^{*}$ profiles with the incidence angle (wind direction) will however affect the accuracy of the CWF. Nevertheless, it is believed that the accuracy of convective heat transfer predictions can be significantly improved by introducing a CWF, compared to the SWF for temperature. This CWF can be of interest for many applications involving highReynolds number convective heat transfer for bluff bodies. 
Defraeye T., Blocken B., Carmeliet J. (2011), An adjusted temperature wall function for turbulent forced convective heat transfer for bluff bodies in the atmospheric boundary layer, Building and Environment 46 (11), 2130-2141. http://dx.doi.org/10.1016/..buildenv.2011.04.013

\subsection{Determining the CWF}

From the $T^{*}-y^{*}$ profiles of LRNM, a temperature CWF can be determined by approximating these data by means of a logarithmic law, i.e. by quantifying its slope $A$ and intercept $B$ :

$\mathrm{T}_{\mathrm{P}}{ }^{*}=\mathrm{A} \ln \mathrm{y}_{\mathrm{P}}{ }^{*}+\mathrm{B}$

The parameters $A$ and $B$ of this logarithmic-law approximation are dependent on the $y_{P} *$ value since two different logarithmic laws can be distinguished in the turbulent region of the boundary layer (see Figure 3, line $\mathrm{A}$ and B), i.e. for $30<y_{P} *<100$ and for $100<y_{P} *<4000$. By comparing this expression with the standard wall-function formulation (Eq.(6)), the parameters $A$ and $B$ can be written as:

$$
\begin{aligned}
& \mathrm{A}=\operatorname{Pr}_{\mathrm{t}} \frac{1}{\kappa} \\
& \mathrm{B}=\operatorname{Pr}_{\mathrm{t}}\left(\frac{1}{\kappa} \ln \mathrm{E}+\mathrm{P}_{\mathrm{J}}\right)
\end{aligned}
$$

This logarithmic-law approximation (Eq.(9)), based on the fitted parameters $A$ and $B$, can be implemented in existing CFD codes in a straightforward way, compared to some other approaches (mentioned a.o. in section 1), since only the temperature wall function has to be adjusted. The implementation of this CWF in a commercial CFD code will be discussed in the next section. Note however that the proposed methodology to determine the adjustment to the standard temperature WF (section 4.1-4.3) is actually generally applicable for any turbulence (and LRNM) model or CFD code.

\subsection{Implementation in a commercial CFD code}

In the commercial CFD code that is used in this study (Fluent 6.3), it is only possible to adjust one parameter in Eq.(10), namely $P r_{t}$. Thereby, it is not possible to implement the logarithmic-law approximation (Eq.(9)) exactly (see line A and B in Figure 3), i.e. by adjusting both the slope and intercept independently. Thereby, the resulting CWF, obtained from approximation of LRNM data and implemented in the commercial code (Fluent 6.3), is written as:

$$
\mathrm{T}_{\mathrm{P}}^{*}=\mathrm{Pr}_{\mathrm{t}, \mathrm{CWF}}\left(\frac{1}{\kappa} \ln \left(\mathrm{Ey}_{\mathrm{P}}^{*}\right)+\mathrm{P}_{\mathrm{J}}\left(\mathrm{Pr}_{\mathrm{t}, \mathrm{CWF}}\right)\right) \quad \mathrm{y}_{\mathrm{P}}^{*}>\mathrm{y}_{\mathrm{T}}{ }^{*}=11.639
$$

where $P r_{t, C W F}$ is the turbulent Prandtl number used by the CWF. Note that $P_{J}$ also changes as it is a function of $\operatorname{Pr}_{t, C W F}$.

The LRNM data used to determine the parameter $P r_{t, C W F}$ in this study are the $T^{*}-y^{*}$ profiles along the centrelines, normal to the vertical surfaces, for different incidence angles $\left(\varphi=0^{\circ}-180^{\circ}\right)$, which are represented in Figure 5. These data are approximated (based on the least-squares method) by a single logarithmic-law CWF (Eq.(11)), i.e. with a constant value of $P r_{t, C W F}$, in the range of $50<y^{*}<500$, which is the typical $y^{*}$ range where wall functions are applied. Thereby, the proposed CWF is actually a compromise between accuracy of the approximation of the LRNM data and the applicability of this approximation throughout the $y *$ range typically found for wall-function grids. The best approximation with these LRNM data is found for $P r_{t, C W F}=1.95$. The resulting logarithmic law is shown in Figure 5 (line C), which is applied for $y_{P}{ }^{*}>11.639$, analogous to Eq.(6), whereas a linear law will still be applied for $y_{P} *<11.639$. Large discrepancies of the CWF with the $T^{*}-y^{*}$ profiles of LRNM are found for 11.639 
Defraeye T., Blocken B., Carmeliet J. (2011), An adjusted temperature wall function for turbulent forced convective heat transfer for bluff bodies in the atmospheric boundary layer, Building and Environment 46 (11), 2130-2141. http://dx.doi.org/10.1016/..buildenv.2011.04.013

$<y_{P} *<50$, since a proper approximation of LRNM data was not envisaged in this region. Therefore, the CWF grids should have relatively high $y_{P} *$ values $(>50)$ for the CWF to be sufficiently accurate, and also to avoid the discontinuity between the linear law (Eq.(5)) and the CWF (Eq.(11), line C) at $y_{P}{ }^{*}=11.639$, where the CWF and the linear law intersect (similar to the SWF). Note that also another set of $T^{*}-y^{*}$ profiles than those of Figure 5 could be used for determining $P r_{t, C W F}$.

In the CFD code that was used, $P r_{t}$ is a specific parameter (called Wall Prandtl Number in Fluent 6.3) which is only used in the expression for the temperature WF (Eq.(6) or Eq.(11)), thus it is different from the turbulent Prandtl number used in the energy equation. This parameter $P r_{t}$ could be easily adjusted (to $\left.P r_{t, C W F}\right)$ since it was directly accessible in the software, where it could be given a constant value ( 0.85 by default, 1.95 for the CWF approach). Note that the proposed CWF and its implementation are also valid for the more recent release of the software, i.e. Fluent 12, since the same models are available here.

\section{Results}

\subsection{Cube}

In Figure 6, the CHTC distribution on the surfaces of the cube, both in a vertical and horizontal centreplane, is given for LRNM, SWFs and CWFs for incidence angles of $0^{\circ}$ and $45^{\circ}$. The aforementioned overprediction of SWFs $\left( \pm 50 \%\right.$ of $\operatorname{CHTC}_{\mathrm{LRNM}}$ for $\varphi=0^{\circ}$, see section 4.1$)$, compared to LRNM, can clearly be noticed, as well as the similarity in distribution of the CHTC by SWFs and LRNM. The CWF results show a much better agreement with LRNM, although some discrepancies still exist for the top surface (at $\varphi=45^{\circ}$ ) and for the front (windward) surface (at $\varphi=45^{\circ}$ ). These discrepancies are due to the fact that the $T^{*}-y^{*}$ profiles in Figure 5 did not agree completely for some incidence angles.

Furthermore, the relative differences between the surface-averaged CHTC, calculated by LRNM $\left(\mathrm{CHTC}_{\mathrm{LRNM}}\right)$ and SWFs or $\mathrm{CWFs}\left(\mathrm{CHTC}_{\mathrm{WF}}\right)$, are compared for a vertical surface and the top surface of the cube as a function of the incidence angle in Figure 7. The accuracy of the CWF is dependent on the incidence angle, both for the vertical surface and the top surface, but is higher than that of SWFs (except for $\varphi=60^{\circ}$ for the vertical surface). The average error of the CWF over all incidence angles (vertical surface: 9\%, top surface: 9\%), with respect to LRNM, is much smaller than that of SWFs (vertical surface: $36 \%$, top surface: $40 \%$ ). The somewhat better accuracy of SWFs for the incidence angles $45^{\circ}$, $60^{\circ}$ and $135^{\circ}$, compared to the other incidence angles, can be explained by the fact that the $T^{*}-y^{*}$ profiles at these angles were somewhat closer to the standard law-of-the-wall (see Figure 5).

Since the approximation of the LRNM data by the CWF (Eq.(11)) does not have the same accuracy over the entire $y^{*}$ range for which it was determined (50-500), there will be some dependency of the CHTC predictions on the $y_{P} *$ value of the wall-function grid. Therefore simulations with two other grids, namely with an overall lower $y_{P}{ }^{*}$ value (Grid 1 ) and higher $y_{P} *$ value (Grid 3), are performed with CWFs and are compared with the original wall-function grid (Grid 2). Note that only the wall distance of the wall-adjacent cells $\left(y_{P}\right)$ differed for these grids, namely $y_{P}=0.03 \mathrm{~m}$ (Grid 1), $0.06 \mathrm{~m}$ (Grid 2) and $0.12 \mathrm{~m}$ (Grid 3). The resulting CHTC and $y_{P} *$ distribution on the surfaces of the cube for a vertical centreplane at an incidence angle of $0^{\circ}$ are given in Figure 8 for these three grids. The differences between the three grids are quite small and the largest differences are found for the grid which has relatively low $y_{P} *$ values 
Defraeye T., Blocken B., Carmeliet J. (2011), An adjusted temperature wall function for turbulent forced convective heat transfer for bluff bodies in the atmospheric boundary layer, Building and Environment 46 (11), 2130-2141. http://dx.doi.org/10.1016/..buildenv.2011.04.013

(Grid 1). This behaviour is not surprising since the accuracy of the CWF approximation decreases significantly for $y_{P}^{*}$ values below 50 (Figure 5). Thereby, wall-function grids with $y_{P} *$ values higher than 50 are recommended when using the proposed CWF since then its performance is quasi independent of the $y_{P} *$ value of the grid.

\subsection{Other bluff-body configurations}

The proposed CWF significantly improves the accuracy of convective heat transfer predictions on the cube surfaces, where already many different flow regimes (flow impingement, separation, reattachment) are present. In addition, the performance of the CWF is evaluated in this section for three other sharpedged bluff-body configurations (see Figure 9) in order to indicate if the CWF is also more generally applicable. The computational domains are built up in a similar way as described in section 2 and also the same boundary conditions are applied.

The relative differences between the surface-averaged CHTC, calculated by LRNM $\left(\mathrm{CHTC}_{\mathrm{LRNM}}\right)$ and SWFs or CWFs $\left(\mathrm{CHTC}_{\mathrm{WF}}\right)$ are compared for all surfaces of these bluff bodies, including the cube, for an incidence angle of $0^{\circ}$ in Figure 10. Also for these bluff bodies, using the CWF improves the convective heat transfer predictions significantly, compared to SWFs. The satisfactory performance of the CWF for various types of sharp-edged bluff bodies and for the many different flow regimes found along their surfaces indicates that it might also perform well for dense bluff-body configurations, such as in urban areas (e.g. street canyons). This however needs to be confirmed by future work.

\section{Discussion}

An adjustment to the standard temperature WF has been determined from validated LRNM data for moderate- to high-Reynolds number convective heat transfer for wall-mounted bluff bodies (buildings) in the atmospheric boundary layer. It is however important to acknowledge the limitations of the proposed CWF:

- This study is performed for bluff bodies with sharp edges. Thereby, the boundary-layer separation points are prescribed by the geometry. In combination with flow at relatively high Reynolds numbers, the overall flow and turbulence fields predicted by WFs and LRNM are quasi similar (see section 1), and thereby also the CHTC distribution over the surfaces. The use of a customised WF, only for temperature, is found to significantly improve the convective heat transfer predictions, compared to SWFs. SWFs can however still be used to predict the velocity and turbulence in the wall-adjacent cell since SWFs do not have a significant effect on the overall flow field for sharp-edged bluff bodies at high Reynolds numbers (see section 1). For bodies without sharp edges however, e.g. cylinders, there can be a distinct difference between the flow fields of both near-wall modelling approaches (LRNM and SWFs) since the predicted boundary-layer separation locations can be significantly different. Thereby, the turbulent kinetic energy in the wall-adjacent cells $\left(k_{P}\right)$, predicted by SWFs, will probably not be similar anymore to that found for LRNM at a specific location. As this is one of the prerequisites to determine the CWF (section 4.1), this type of body is not suited to determine a CWF (as in section 4). This 
Defraeye T., Blocken B., Carmeliet J. (2011), An adjusted temperature wall function for turbulent forced convective heat transfer for bluff bodies in the atmospheric boundary layer, Building and Environment 46 (11), 2130-2141. http://dx.doi.org/10.1016/i.buildenv.2011.04.013

difference in flow field prediction will not allow comparing CHTC results of the CWF and LRNM. Nevertheless, the use of the CWF (determined for a sharp-edged body) for bodies without sharp edges will not inherently lead to less accurate convective heat transfer predictions, compared to SWFs, since the flow fields for SWFs and CWFs are the same.

- Since only a temperature CWF is proposed, the same limitations as for SWFs apply for the flow field prediction, namely a less accurate prediction of wall friction and the lack of a generalised treatment over the entire $y^{*}$ range. Thereby, the CWF is not applicable throughout the lower part of the boundary layer, i.e. within the viscosity-affected region.

- The CWF is determined for forced convective flow and thereby its validity for natural or mixed convection cases should be verified. This research is currently ongoing. Note however that the SWFs, including the one for temperature, were also derived for forced convection.

- The CWF is not derived analytically but is actually based on validated numerical data, namely the $T^{*}-y^{*}$ profiles of LRNM. The dependency of these profiles on the incidence angle affects the accuracy of the CWF to some extent.

- In the CFD code that is used, only one parameter can be adjusted in the logarithmic law (Eq.(6)), namely $P r_{t}$. Thereby, a detailed approximation of the LRNM data by means of a customised lawof-the-wall, which is valid throughout the entire $y^{*}$ range, is not possible. The proposed CWF, i.e. a logarithmic law, is only applicable for $y_{P} *$ values above about 50 . Note that other CFD codes might not exhibit this limitation, which will improve the accuracy of the CWF.

- The proposed CWF (with $\operatorname{Pr}_{t, C W F}=1.95$ ) is based on LRNM data $\left(T^{*}-y^{*}\right.$ profiles) obtained with the realizable k- $\varepsilon$ model. Since the LRNM $T^{*}-y^{*}$ profiles are inherently linked to the $k$ and $T$ distributions in the boundary layer (see section 4.1), which are turbulence-model dependent, the CWF should in principle be used in combination with this specific turbulence model. The proposed CWF $\left(\operatorname{Pr}_{t, C W F}=1.95\right)$ is however also expected to perform well for turbulence models which are similar to the one used here. Therefore it is evaluated with the standard k- $\varepsilon$ model [60], on which the realizable $\mathrm{k}-\varepsilon$ model is actually based and which is also available in most CFD codes, in Figure 11. Although its CHTC distribution differs to some extent, which is related to slightly different flow field predictions on top and side surfaces, its overall magnitude agrees well with the realizable $\mathrm{k}-\varepsilon$ model results. This agreement indicates that the standard $\mathrm{k}-\varepsilon$ model with CWFs can successfully be used with $P r_{t, C W F}=1.95$. If a fundamentally different turbulence model is used with CWFs, a similar methodology as explained in section 4 can be used to estimate $P r_{t, C W F}$. Future studies will therefore evaluate this CWF approach for other turbulencemodel families.

- The CWF improves the convective heat transfer predictions in the boundary layer, compared to SWFs. However, the CWF does not improve inaccuracies in heat transfer related to the flow field prediction by the turbulence model (e.g. in the wake of the building). If a higher accuracy is required here, other (RANS) turbulence models or modelling approaches (e.g. LES) should be applied (and validated). Such models can however increase the computational cost significantly, which is an important issue in large-scale building engineering or environmental studies (e.g. 
Defraeye T., Blocken B., Carmeliet J. (2011), An adjusted temperature wall function for turbulent forced convective heat transfer for bluff bodies in the atmospheric boundary layer, Building and Environment 46 (11), 2130-2141. http://dx.doi.org/10.1016/i.buildenv.2011.04.013

$[6,7,19-22])$. It is however important to note that, regardless of the turbulence model or turbulence modelling approach, the importance of adjusted temperature wall functions with improved accuracy, compared to SWFs, remains.

Apart from these limitations, the use of the proposed CWF could be justified and the improvement over SWFs was indicated. The main reasons for its good performance are that the overall flow fields for LRNM and WFs are approximately similar, resulting in a similar CHTC distribution, and that a quasi universal, logarithmic-like, behaviour is found for the $T^{*}-y^{*}$ profiles of LRNM. Thereby, the CWF approach combines an increased wall-function accuracy for thermal calculations with the advantages of WFs, namely easier grid generation, since very fine cells in the near-wall region are avoided, and grids with less computational cells, reducing the computational time. The number of cells for the four bluffbody configurations that are evaluated in this study are compared in Table 2, for LRNM and WFs. The wall-function grids have on average about $30 \%$ less cells than the LRNM grids, which is a significant reduction. Furthermore, the implementation of the CWF in the CFD code was straightforward and simple, namely by adjusting one parameter (but preferably two parameters, see Eq.(9)) in the expression for the temperature WF (Eq.(6)), which could be done directly in the software in this study. This ease of implementation is an advantage since most commercial CFD codes offer limited access to the code itself. Thereby, the CWF approach should be applied from the viewpoint of using WFs which have an increased accuracy regarding convective heat transfer and which are easily implementable in CFD codes.

It has to be mentioned that an improvement over SWFs, regarding CHTC predictions, can also be obtained by using other adjusted WFs (see Blocken et al. [15]), such as those of Kim and Choudhury [38]. Also note that an analogous approach can be applied to determine a CWF for mass transfer in the boundary layer.

\section{Conclusions}

In this paper, an adjustment to the standard temperature wall function was proposed for applications for forced convective heat transfer at the surfaces of typical wall-mounted (sharp-edged) bluff bodies in turbulent boundary layers at moderate to high Reynolds numbers, such as buildings in the atmospheric boundary layer. The aim was to combine the advantage of the use of WFs over LRNM, namely a lower grid resolution in the near-wall region, together with an increased accuracy for convective heat transfer predictions, compared to standard wall functions (SWFs). The methodology to determine this customised temperature wall function (CWF) from validated (LRNM) numerical data was explained, where this CWF was based on a logarithmic law. This CWF could be implemented with only simple adjustments to the CFD code (Fluent in this study), which is advantageous when using commercial CFD codes, where usually only limited access to the code is possible. Its performance was evaluated for several bluff-body configurations, including a cube. SWFs yielded deviations of about $40 \%$ for the CHTC, compared to LRNM. With the CWF however, these deviations were generally reduced to about $10 \%$ or lower. This CWF approach showed that a significant improvement in accuracy can be obtained, compared to SWFs. Although one of the major limitations of SWFs was partly alleviated in this way, namely its reduced accuracy for convective heat transfer, another limitation, i.e. the applicability of WFs only within the 
Defraeye T., Blocken B., Carmeliet J. (2011), An adjusted temperature wall function for turbulent forced convective heat transfer for bluff bodies in the atmospheric boundary layer, Building and Environment 46 (11), 2130-2141. http://dx.doi.org/10.1016/..buildenv.2011.04.013

logarithmic region, was not addressed. The proposed CWF approach will be useful for computationallyexpensive large-scale building engineering or environmental studies at high Reynolds numbers involving heat transfer, which are bound to rely on WFs to resolve the boundary layer, but where accurate convective heat transfer predictions are required.

\section{Acknowledgements}

This research was funded by the Government of Flanders. As a Flemish government institution, IWTFlanders (Institute for the Promotion of Innovation by Science and Technology in Flanders) supports and stimulates industrial research and technology transfer in the Flemish industry. Their contribution is gratefully acknowledged. This sponsor had no involvement in: the study design, in the collection, analysis and interpretation of data; in the writing of the manuscript; and in the decision to submit the manuscript for publication.

\section{References}

[1] Takebayashi H, Moriyama M. Surface heat budget on green roof and high reflection roof for mitigation of urban heat island. Build Environ 2007;42(8):2971-9.

[2] Sailor DJ, Dietsch N. The urban heat island Mitigation Impact Screening Tool (MIST). Environ Modell Softw 2007;22(10):1529-1541.

[3] Liu Y, Harris DJ. Full-scale measurements of convective coefficient on external surface of a low-rise building in sheltered conditions. Build Environ 2007;42(7):2718-2736.

[4] Palyvos JA. A survey of wind convection coefficient correlations for building envelope energy systems' modeling. Appl Therm Eng 2008;28(8-9):801-8.

[5] Defraeye T, Carmeliet J. A methodology to assess the influence of local wind conditions and building orientation on the convective heat transfer at building surfaces. Environ Modell Softw 2010;25(12):1813-1824.

[6] Hussein AS, El-Shishiny H. Influences of wind flow over heritage sites: A case study of the wind environment over the Giza Plateau in Egypt. Environ Modell Softw 2009;24(3):389-410.

[7] van Hooff T, Blocken B. Coupled urban wind flow and indoor natural ventilation modelling on a high-resolution grid: a case study for the Amsterdam ArenA stadium. Environ Modell Softw 2010;25(1):51-65.

[8] Chilton TH, Colburn AP. Mass transfer (absorption) coefficients. Ind Eng Chemistry 1934;26:1183-7.

[9] Blocken B, Carmeliet J. A review of wind-driven rain research in building science. J Wind Eng Ind Aerod 2004;92(13):1079-1130.

[10] Chyu MK, Natarajan V. Local heat/mass transfer distributions on the surface of a wall-mounted cube. T ASME: J Heat Trans 1991;13(4):851-7.

[11] Meinders ER, Hanjalic K, Martinuzzi RJ. Experimental study of the local convection heat transfer from a wall-mounted cube in turbulent channel flow. T ASME: J Heat Trans 1999;121(3):564-573.

[12] Morris GK, Garimella SV. Composite correlations for convective heat transfer from arrays of threedimensional obstacles. Int J Heat Mass Tran 1997;40(2):493-8. 
Defraeye T., Blocken B., Carmeliet J. (2011), An adjusted temperature wall function for turbulent forced convective heat transfer for bluff bodies in the atmospheric boundary layer, Building and Environment 46 (11), 2130-2141. http://dx.doi.org/10.1016/..buildenv.2011.04.013

[13] Nakamura H, Igarashi T, Tsutsui T. Local heat transfer around a wall-mounted cube in the turbulent boundary layer. Int J Heat Mass Tran 2001;44(18):3385-3395.

[14] Quintela DA, Viegas DX. Convective heat losses from buildings. In: Cermak JE, Davenport AG, Plate EJ, Viegas DX, editors. Wind Climate in Cities. The Netherlands: Kluwer Academic Publishers; 1995, p. 503-522.

[15] Blocken B, Defraeye T, Derome D, Carmeliet J. High-resolution CFD simulations for forced convective heat transfer coefficients at the facade of a low-rise building. Build Environ 2009;44(12):2396-2412.

[16] Defraeye T, Blocken B, Carmeliet J. Convective heat transfer coefficients for exterior building surfaces: Existing correlations and CFD modeling. Energ Convers Manage 2011;52(1):512-522.

[17] Seeta Ratnam G, Vengadesan S. Performance of two equation turbulence models for prediction of flow and heat transfer over a wall mounted cube. Int J Heat Mass Tran 2008;51(11-12):2834-2846.

[18] Hanjalic K, Kenjeres S. Some developments in turbulence modeling for wind and environmental engineering. J Wind Eng Ind Aerod 2008;96(10-11):1537-1570.

[19] Briggen PM, Blocken B, Schellen HL. Wind-driven rain on the facade of a monumental tower: Numerical simulation, full-scale validation and sensitivity analysis. Build Environ 2009;44(8):16751690.

[20] Gousseau P, Blocken B, Stathopoulos T, van Heijst GJF. CFD simulation of near-field pollutant dispersion on a high-resolution grid: A case study by LES and RANS for a building group in downtown Montreal. Atmos Environ 2011:45(2):428-438.

[21] van Hooff T, Blocken B, van Harten M. 3D CFD simulations of wind flow and wind-driven rain shelter in sports stadia: Influence of stadium geometry. Build Environ 2011;46(1):22-37.

[22] Neofytou P, Venetsanos AG, Vlachogiannis D, Bartzis JG, Scaperdas A. CFD simulations of the wind environment around an airport terminal building. Environ Modell Softw 2006;21(4):520-4.

[23] Launder BE, Spalding DB. The numerical computation of turbulent flows. Comput Method Appl M Eng 1974;3(2):269-289.

[24] Franke J. Hellsten A. Schlünzen H. Carissimo B. Best practice guideline for the CFD simulation of flows in the urban environment, COST Action 732: Quality assurance and improvement of microscale meteorological models, Hamburg, Germany; 2007.

[25] Casey M. Wintergerste T. Best Practice Guidelines. ERCOFTAC Special Interest Group on “Quality and Trust in Industrial CFD”. ERCOFTAC; 2000.

[26] Launder BE. On the computation of convective heat transfer in complex turbulent flows. T ASME: J Heat Trans 1988;110:1112-1128.

[27] Liakopoulos A. Explicit representations of the complete velocity profile in a turbulent boundary layer. AIAA J 1984;22:844-6.

[28] Musker AJ. Explicit expression for the smooth wall velocity distribution in a turbulent boundary layer. AIAA J 1979;17:655-7.

[29] Shih TH, Povinelli LA, Liu NS. Application of generalized wall function for complex turbulent flows. J Turb 2003;4(1):1-16. 
Defraeye T., Blocken B., Carmeliet J. (2011), An adjusted temperature wall function for turbulent forced convective heat transfer for bluff bodies in the atmospheric boundary layer, Building and Environment 46 (11), 2130-2141. http://dx.doi.org/10.1016/..buildenv.2011.04.013

[30] Spalding DB. A single formula for the law of the wall. T ASME: J Appl Mech 1961;28(3):455-8.

[31] Popovac M, Hanjalic K. Compound wall treatment for RANS computation of complex turbulent flows and heat transfer. Flow Turbul Combust 2007;78(2):177-202.

[32] Albets-Chico X, Pérez-Segarra CD, Oliva A, Bredberg J. Analysis of wall-function approaches using two-equation turbulence models. Int J Heat Mass Tran 2008;51(19-20):4949-4957.

[33] Amano RS. Development of turbulence near-wall model and its application to separated and reattached flows. Numer Heat Tr A - Appl 1984;7(1):59-76.

[34] Balaji C, Hölling M, Herwig H. A temperature wall function for turbulent mixed convection from vertical, parallel plate channels. Int J Therm Sci 2008;47(6):723-9.

[35] Chieng CC, Launder BE. On the calculation of turbulent heat transport downstream from an abrupt pipe expansion. Numer Heat Tr A - Appl 1980;3(2):189-207.

[36] Ciofalo M, Collins MW. k- $\varepsilon$ predictions of heat transfer in turbulent recirculating flows using an improved wall treatment. Numer Heat Tr B - Fund 1989;15(1):21-47.

[37] Johnson RW, Launder BE. Discussion of "On the calculation of turbulent heat transport downstream from an abrupt pipe expansion". Numer Heat Tr B - Fund 1982;5(4):493-6.

[38] Kim SE, Choudhury D. A near-wall treatment using wall functions sensitized to pressure gradient. In: ASME Fluids Engineering Division, Separated and Complex Flows Vol. 217. ASME; 1995, p. 273-280.

[39] Craft TJ, Gant SE, Iacovides H, Launder BE. A new wall function strategy for complex turbulent flows. Numer Heat Tr B - Fund 2004;45(4):301-318.

[40] Craft TJ, Gerasimov AV, Iacovides H, Launder BE. Progress in the generalization of wall-function treatments. Int J Heat Fluid Fl 2002;23(2):148-160.

[41] Knopp T, Alrutz T, Schwamborn D. A grid and flow adaptive wall-function method for RANS turbulence modeling. J Comput Phys 2006;220(1):19-40.

[42] Suga K, Craft TJ, Iacovides H. An analytical wall-function for turbulent flows and heat transfer over rough walls. Int J Heat Fluid Fl 2006;27(5):852-866.

[43] Kalitzin G, Medic G, Iaccarino G, Durbin P. Near-wall behavior of RANS turbulence models and implications for wall functions. J. Comput Phys 2005;204(1):265-291.

[44] Kim J-Y, Ghajar AJ, Tang C, Foutch GL. Comparison of near-wall treatment methods for high Reynolds number backward-facing step flow. Int J Comp Fluid D 2005;19(7):493-500.

[45] Murakami S. Comparison of various turbulence models applied to a bluff body. J Wind Eng Ind Aerod 1993;46-47:21-36.

[46] Defraeye T, Blocken B, Carmeliet J. CFD analysis of convective heat transfer at the surfaces of a cube immersed in a turbulent boundary layer. Int J Heat Mass Tran 2010;53(1-3):297-308.

[47] Defraeye T, Blocken B, Koninckx E, Hespel P, Carmeliet J. CFD analysis of cyclist aerodynamics: Performance of different turbulence-modelling and boundary-layer modelling approaches. J Biomech 2010;43(12):2281-7. 
Defraeye T., Blocken B., Carmeliet J. (2011), An adjusted temperature wall function for turbulent forced convective heat transfer for bluff bodies in the atmospheric boundary layer, Building and Environment 46 (11), 2130-2141. http://dx.doi.org/10.1016/..buildenv.2011.04.013

[48] Tominaga Y, Mochida A, Yoshie R, Kataoka H, Nozu T, Yoshikawa M, Shirasawa T. AIJ guidelines for practical applications of CFD to pedestrian wind environment around buildings. J Wind Eng Ind Aerod 2008;96(10-11):1749-1761.

[49] Richards PJ, Hoxey RP. Appropriate boundary conditions for computational wind engineering models using the k- $\varepsilon$ turbulence model. J Wind Eng Ind Aerod 1993;46-47:145-153.

[50] Wieringa J. Updating the Davenport roughness classification. J Wind Eng Ind Aerod 1992;4144:357-368.

[51] Fluent. Fluent 6.3 User's Guide. Lebanon - New Hampshire. USA; 2006.

[52] Blocken B, Stathopoulos T, Carmeliet J. CFD simulation of the atmospheric boundary layer: wall function problems. Atmos Environ 2007;41(2);238-252.

[53] Blocken B, Carmeliet J, Stathopoulos T. CFD evaluation of the wind speed conditions in passages between buildings - effect of wall-function roughness modifications on the atmospheric boundary layer flow. J Wind Eng Ind Aerod 2007;95(9-11):941-962.

[54] Shih TH, Liou WW, Shabbir A, Yang Z, Zhu J. A new k- $\varepsilon$ eddy viscosity model for high Reynolds number turbulent flows. Comput Fluids 1995;24(3):227-238.

[55] Wolfshtein M. The velocity and temperature distribution in one-dimensional flow with turbulence augmentation and pressure gradient. Int J Heat Mass Tran 1969;12(3):301-318.

[56] Iaccarino G, Ooi A, Durbin PA, Behnia M. Reynolds averaged simulation of unsteady separated flow. Int J Heat Fluid Fl 2003;24(2):147-156.

[57] Murakami S, Mochida A, Ooka R, Kato S, Iizuka S. Numerical prediction of flow around a building with various turbulence models: comparison of k- $\mathrm{EVM}$, ASM, DSM and LES with wind tunnel tests. ASHRAE Trans 1996;102(1):741-753.

[58] Gromke C, Buccolieri R, Di Sabatino S, Ruck B. Dispersion study in a street canyon with tree planting by means of wind tunnel and numerical investigations - Evaluation of CFD data with experimental data. Atmos Environ 2008;42(37):8640-8650.

[59] Karava P, Jubayer CM, Savory E. Numerical modelling of forced convective heat transfer from the inclined windward roof of an isolated low-rise building with application to photovoltaic/thermal systems. Appl Therm Eng. In Press (doi:10.1016/j.applthermaleng.2011.02.042) 2011.

[60] Launder BE, Spalding DB. Lectures in mathematical models of turbulence. London. UK: Academic Press; 1972. 
Defraeye T., Blocken B., Carmeliet J. (2011), An adjusted temperature wall function for turbulent forced convective heat transfer for bluff bodies in the atmospheric boundary layer, Building and Environment 46 (11), 2130-2141. http://dx.doi.org/10.1016/i.buildenv.2011.04.013

Figures

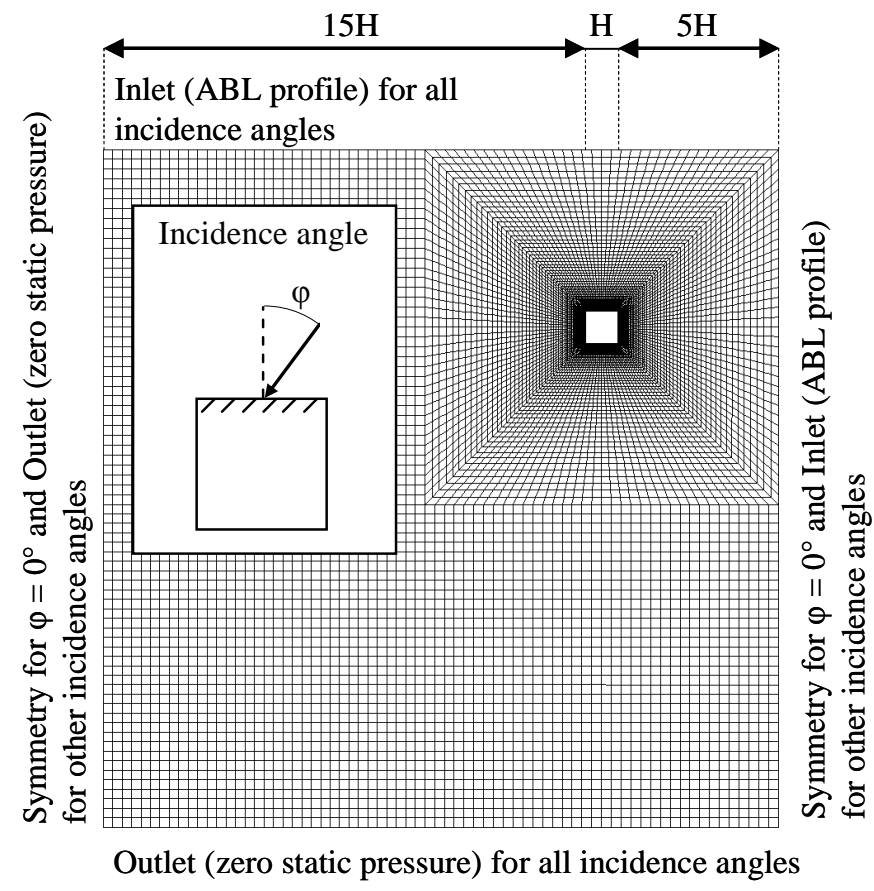

Figure 1. Top view of the computational domain and grid $(H=$ cube height) with specification of the boundary conditions. The height of the domain is $6 \mathrm{H}$.
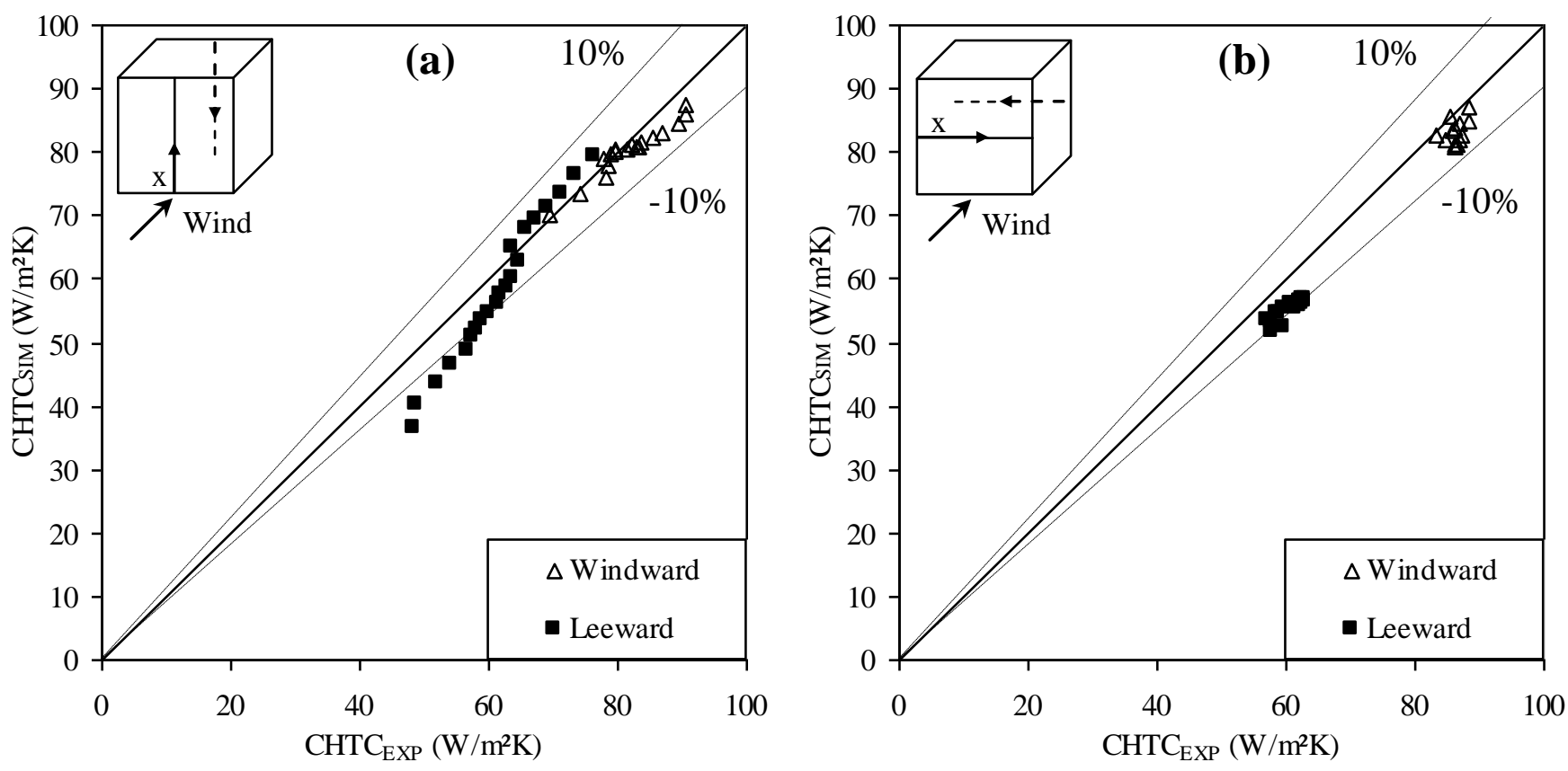

Figure 2. Comparison of the CHTC on the surfaces of the cube of the wind-tunnel experiment of

Meinders et al. [11] $\left(\mathrm{CHTC}_{\mathrm{EXP}}\right)$ and the CFD validation study of Defraeye et al. [46] $\left(\mathrm{CHTC}_{\mathrm{SIM}}\right)$ in a vertical (a) and horizontal (b) centreplane on the windward and leeward surfaces. Note that only the results in the central region of the surface $(0.2<\mathrm{x} / \mathrm{H}<0.8)$ are shown. 
Defraeye T., Blocken B., Carmeliet J. (2011), An adjusted temperature wall function for turbulent forced convective heat transfer for bluff bodies in the atmospheric boundary layer, Building and Environment 46 (11), 2130-2141. http://dx.doi.org/10.1016/..buildenv.2011.04.013

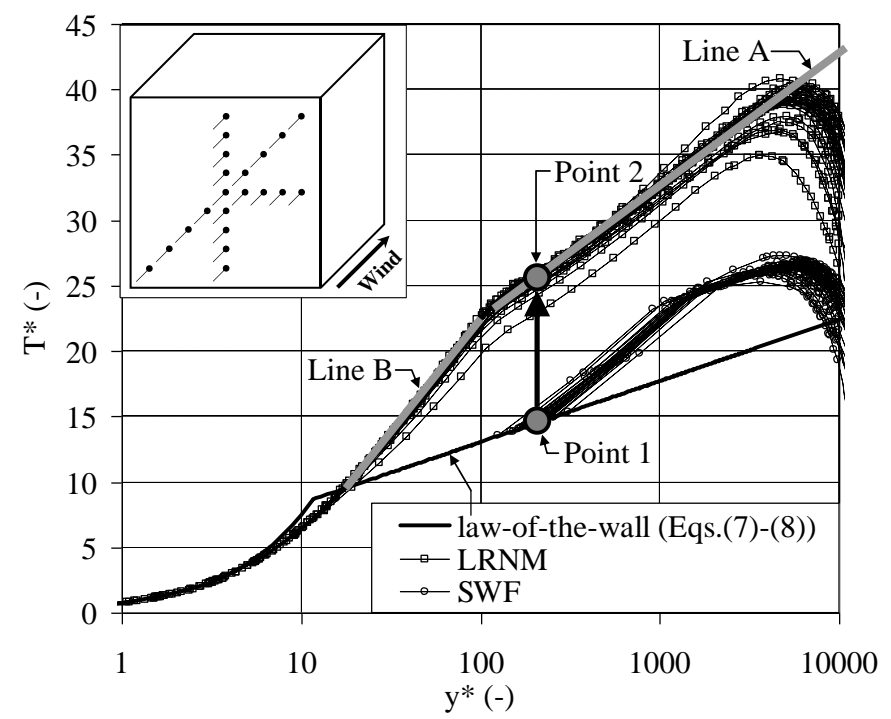

Figure 3. Dimensionless temperature profiles at different positions on the windward surface $(\varphi=$ $0^{\circ}$ ) of the cube along lines normal to the surface, as a function of the $y *$ value (logarithmic scale), for LRNM and SWFs. 
Defraeye T., Blocken B., Carmeliet J. (2011), An adjusted temperature wall function for turbulent forced convective heat transfer for bluff bodies in the atmospheric boundary layer, Building and Environment 46 (11), 2130-2141. http://dx.doi.org/10.1016/..buildenv.2011.04.013

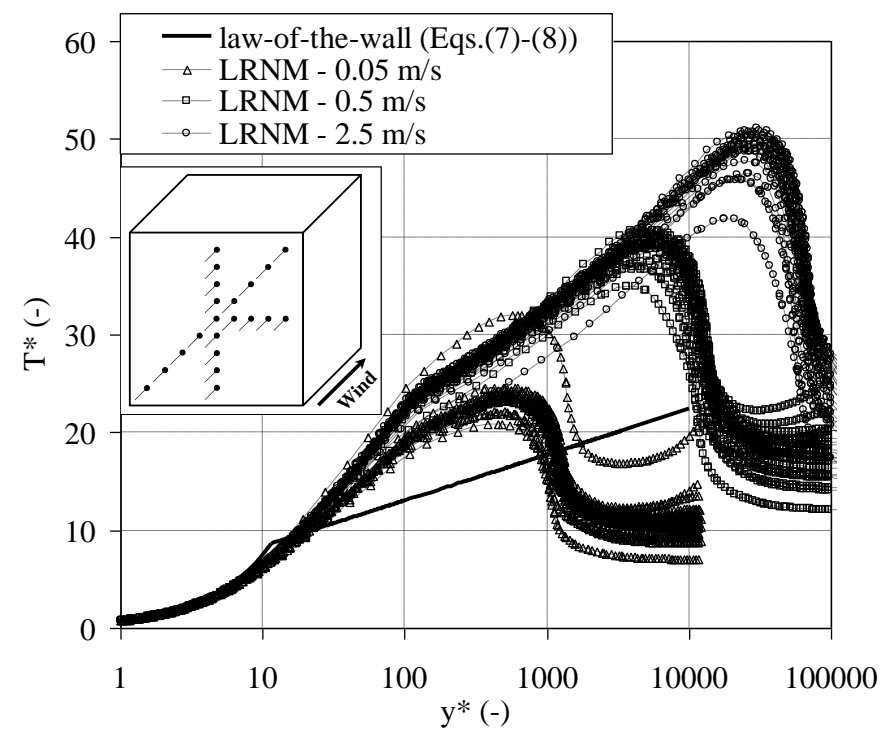

Figure 4. Dimensionless temperature profiles at different positions on the windward surface $(\varphi=$ $0^{\circ}$ ) of the cube along lines normal to the surface, as a function of the $y^{*}$ value (logarithmic scale), for LRNM for $0.05,0.5$ and $2.5 \mathrm{~m} / \mathrm{s}$.

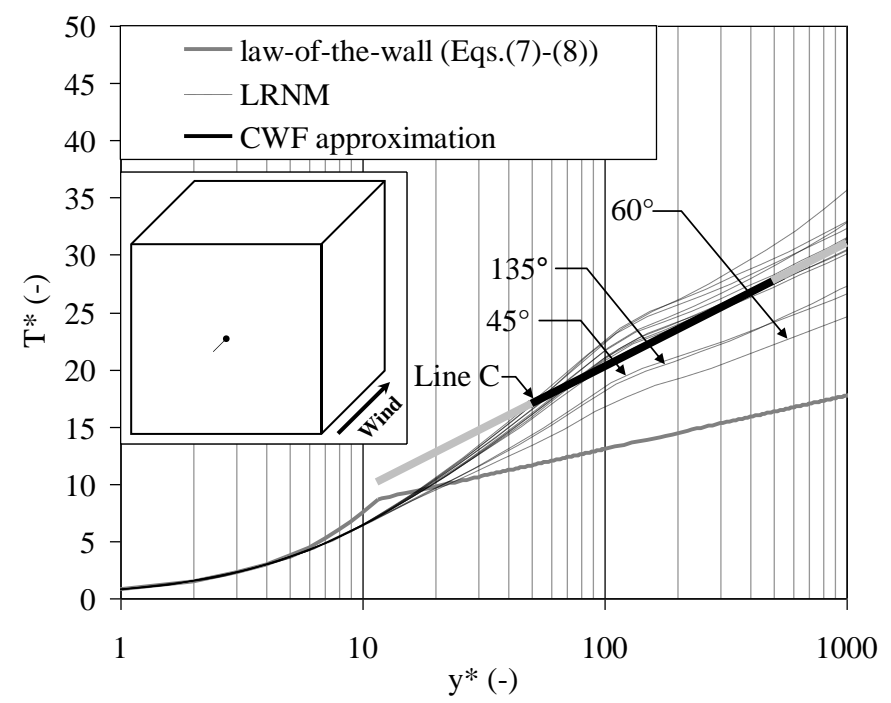

Figure 5. Dimensionless temperature profiles along a line normal to the surface at the centre of a vertical surface of the cube, as a function of the $y^{*}$ value (logarithmic scale), for LRNM for different incidence angles (dotted lines), namely for $\varphi=0^{\circ}-180^{\circ}$ in steps of $15^{\circ}$. The incidence angles which show distinct differences with the rest are marked. The CWF approximation (line C) of the LRNM data for the different incidence angles, within the range $50<y^{*}<500$, is also shown (bold black line) as well as the extrapolation of this CWF approximation towards $y^{*}$ values up to 1000 and down to 11.639 (bold light grey lines). 

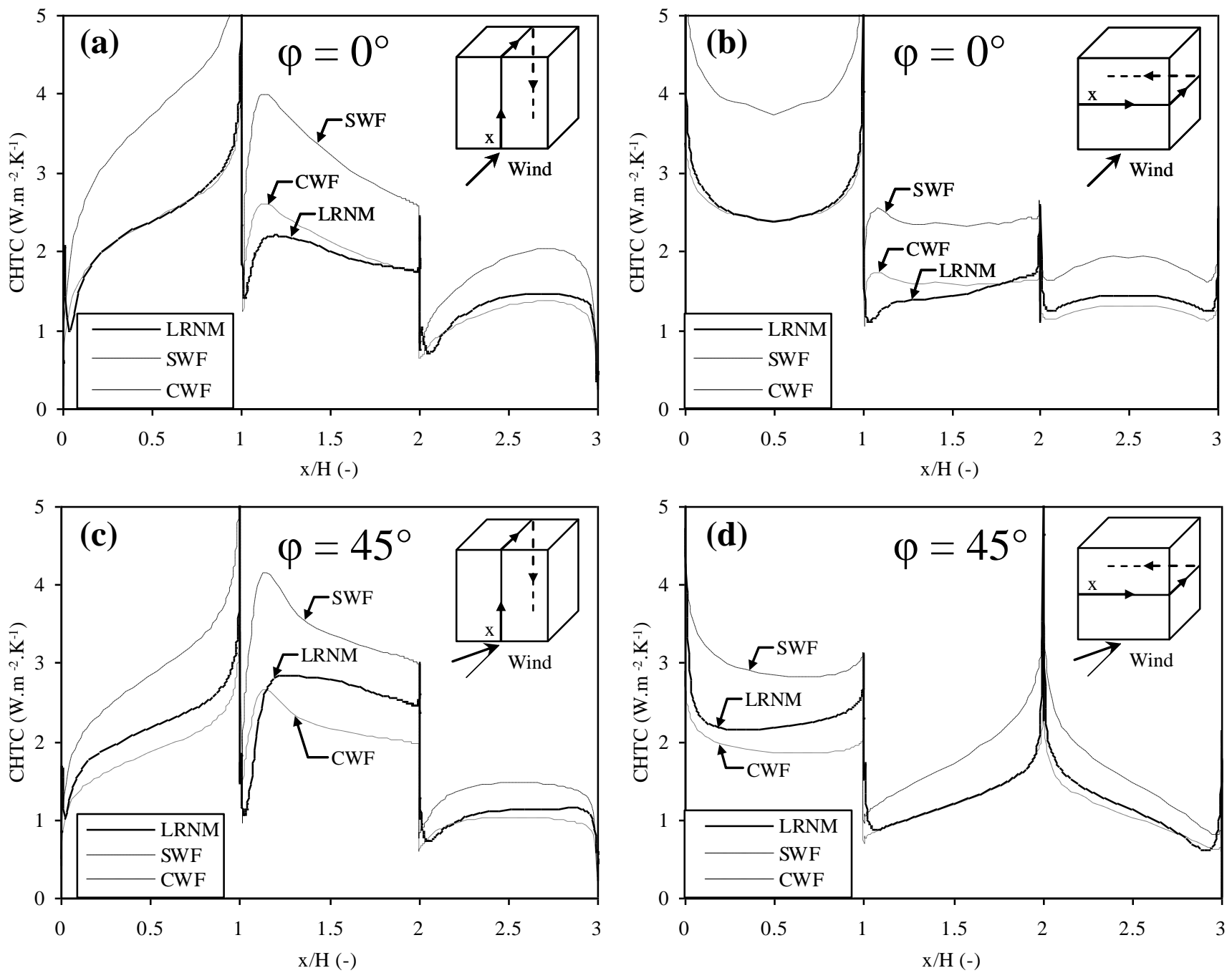

Figure 6. CHTC distribution on the surfaces of the cube (for LRNM, SWF and CWF) in a vertical ((a) and (c)) and horizontal ((b) and (d)) centreplane for incidence angles of $0^{\circ}$ and $45^{\circ}$. 


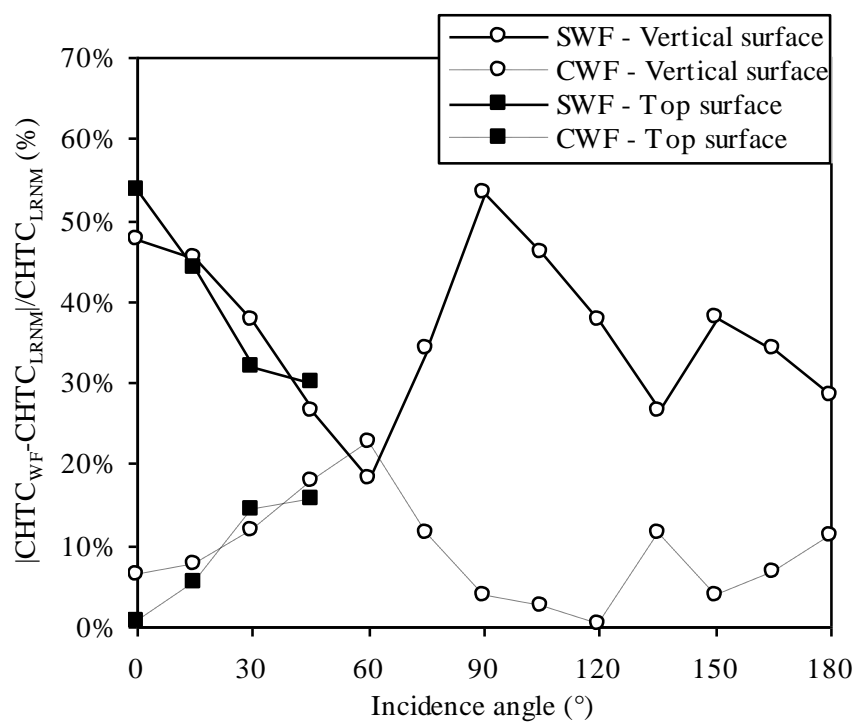

Figure 7. Relative difference between the surface-averaged CHTC, calculated by LRNM $\left(\mathrm{CHTC}_{\mathrm{LRNM}}\right)$ and $\mathrm{SWF}$ or $\mathrm{CWF}\left(\mathrm{CHTC}_{\mathrm{WF}}\right)$, for a vertical surface and the top surface of the cube as a function of the incidence angle. Due to symmetry, only data for incidence angles up to $45^{\circ}$ are given for the top surface.

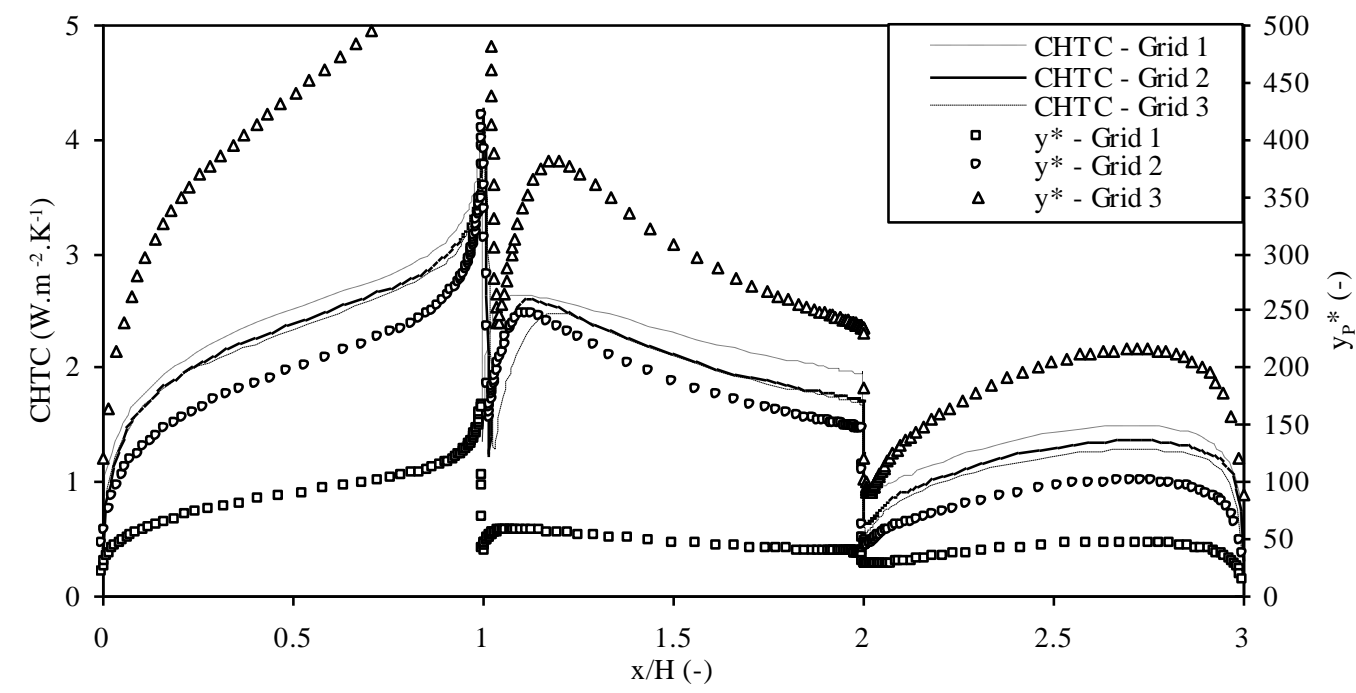

Figure 8. CHTC distribution on the surfaces of the cube in a vertical centreplane for an incidence angle of $0^{\circ}$ for CWF for three different grids (Grid 2 is the one that is used for all the other wallfunction simulations in this paper) together with the distribution of $y_{P} *$ (i.e. in the wall-adjacent cell) for these grids. 

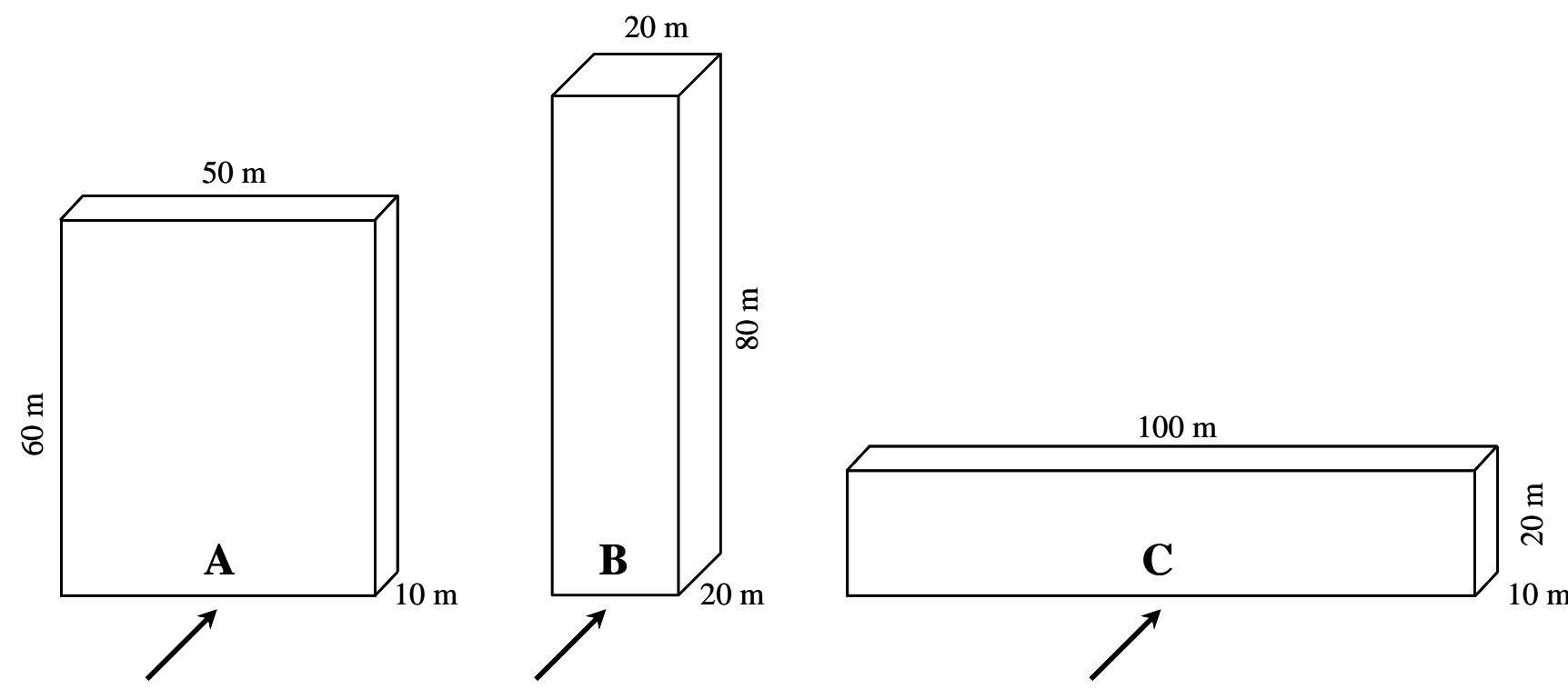

Figure 9. Three bluff-body configurations (body A, B and C) with their dimensions. The wind direction for an incidence angle of $0^{\circ}$ is indicated.

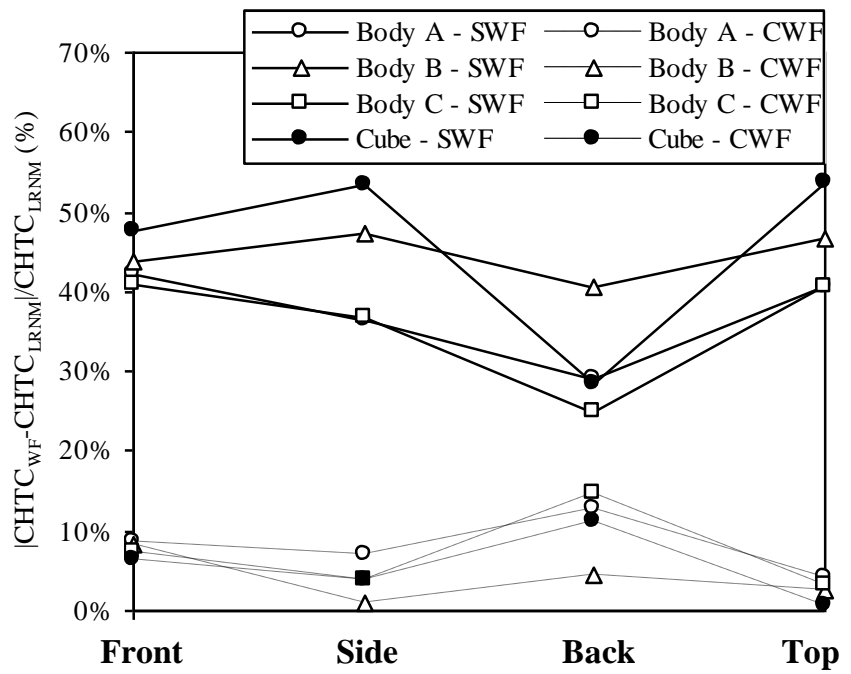

Figure 10. Relative difference between the surface-averaged CHTC, calculated by LRNM $\left(\right.$ CHTC $\left._{\mathrm{LRNM}}\right)$ and SWF or CWF $\left(\mathrm{CHTC}_{\mathrm{WF}}\right)$, for the different surfaces $($ Front $=$ windward surface, Back = leeward surface) of the three bluff-body configurations presented in Figure 8 and for the cube for an incidence angle of $0^{\circ}$. 
Defraeye T., Blocken B., Carmeliet J. (2011), An adjusted temperature wall function for turbulent forced convective heat transfer for bluff bodies in the atmospheric boundary layer, Building and Environment 46 (11), 2130-2141. http://dx.doi.org/10.1016/i.buildenv.2011.04.013
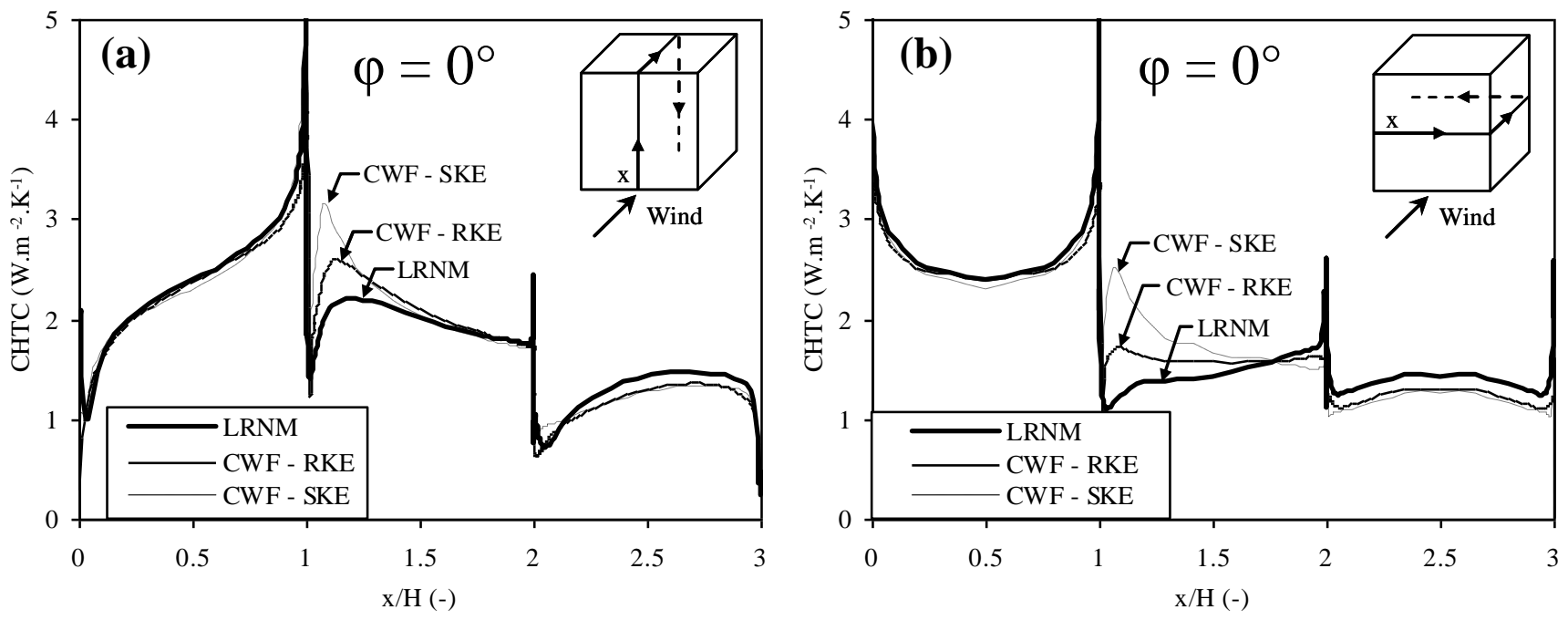

Figure 11. CHTC distribution on the surfaces of the cube in a vertical (a) and horizontal (b) centreplane for an incidence angle of $0^{\circ}$ for LRNM and CWF (with the realizable $k-\varepsilon$ model (RKE) and the standard $k-\varepsilon$ model (SKE)). 
Defraeye T., Blocken B., Carmeliet J. (2011), An adjusted temperature wall function for turbulent forced convective heat transfer for bluff bodies in the atmospheric boundary layer, Building and Environment 46 (11), 2130-2141. http://dx.doi.org/10.1016/..buildenv.2011.04.013

Tables

Table 1: Relative difference of the surface-averaged CHTC on the surfaces of a cube between the CFD validation study of Defraeye et al. [46] $\left(\right.$ CHTC $\left._{\text {SIM }}\right)$ and the wind-tunnel experiment of Meinders et al. [11] (CHTC EXP $_{\text {). }}$

\begin{tabular}{lc}
\hline Surface & $\left|\mathrm{CHTC}_{\mathrm{SIM}^{-}} \mathrm{CHTC}_{\mathrm{EXP}}\right| / \mathrm{CHTC}_{\mathrm{EXP}}$ \\
\hline Windward & $7 \%$ \\
\hline Leeward & $21 \%$ \\
\hline Side & $12 \%$ \\
\hline Top & $33 \%$ \\
\hline
\end{tabular}

Table 2. Number of cells for the four bluff-body configurations evaluated in this paper (see Figure 1 and Figure 8) for LRNM and wall-function grids, together with the relative difference between both (normalized with the number of cells of LRNM).

\begin{tabular}{lccc}
\hline Bluff body & \multicolumn{2}{c}{ Number of cells } & Relative \\
& LRNM & WF & difference $(\%)$ \\
\hline Cube & $2.67 \times 10^{6}$ & $1.57 \times 10^{6}$ & 41 \\
\hline Body A & $4.55 \times 10^{6}$ & $3.07 \times 10^{6}$ & 33 \\
\hline Body B & $5.36 \times 10^{6}$ & $3.93 \times 10^{6}$ & 27 \\
\hline Body C & $4.20 \times 10^{6}$ & $2.72 \times 10^{6}$ & 35
\end{tabular}

